\title{
Consistency in European seabass coping styles: A life history approach
}

\author{
Ferrari Sébastien ${ }^{1,2,{ }^{*}}$, Millot Sandie ${ }^{1}$, Leguay Didier ${ }^{1}$, Chatain Béatrice ${ }^{2,3}$, Bégout Marie-Laure ${ }^{1}$ \\ ${ }^{1}$ Ifremer, Laboratoire Ressources Halieutiques, Place Gaby Coll, BP7, 17137 L'Houmeau, La Rochelle, \\ 2 UMR 110 INTREPID, Ifremer-Cirad, 34000 Montpellier, France \\ ${ }^{3}$ Station Expérimentale d'Aquaculture Ifremer, Laboratoire de Recherche Piscicole de Méditerranée, \\ Chemin de Maguelone, 34250 Palavas-Les-Flots, France
} France

*Corresponding author : Sébastien Ferrari, email address : sebferrari@hotmail.fr

\begin{abstract}
:
Recent years have seen a growth of interest in the consistent differences in individual behaviour over time and contexts constituting so-called "individual coping styles". An understanding of this inter-individual variation is essential to improve our knowledge of the adaptive value of behaviour. Coping styles may have implications in diverse fields, so the development of appropriate screening methods for each species appears to be the most effective way to extend our knowledge and to incorporate behavioural responses into selection-based breeding programmes, to improve the domestication and welfare of farmed fish. We tested 30 juvenile seabass (Dicentrarchus labrax) at least twice in individual-based tests (feeding recovery in isolation, aggressiveness, exploration in a T-maze and net restraint) and group-based tests (risk-taking and hypoxia sorting), to assess coping style consistency in the short and long term and between tests. The results of individual-based tests were inconsistent over time and between tests in our set-up: the time between repeat tests, learning and species-specific behavioural responses appeared to have a major impact. By contrast, the results of group-based tests, such as risk-taking and hypoxia sorting, appeared to be consistent (both in the short and long term). These tests therefore appeared to be the most relevant for the characterisation of coping style in European seabass. Furthermore, the results of these tests were also predictive of cortisol stress response. These tests are simple to perform and can be used to screen large numbers of fish, the first step in selection programmes including behavioural profiles
\end{abstract}

\section{Highlights}

- We characterized coping styles in European seabass. We showed evidence for behavioural consistency in group based tests. Results may also be accounted for by species specificity in behavioural responses.

Keywords : behavioural plasticity, repeatability, life stages, Dicentrarchus labrax behavioural plasticity, repeatability, life stages, Dicentrarchus labrax 


\section{INTRODUCTION}

There has been an increase in interest in the consistent differences in individual behaviour over time and contexts. Consistency is the predictability of repeated measurements for the same individuals, and it can be used to provide estimates for populations (Nunnally, 1967; Réale et al., 2007). It has been clearly shown that, within species (vertebrates or invertebrates), individuals may react differently to the same situation. This individual variability is generated by a collection of correlated physiological and behavioural responses, known as the coping strategy or coping style (Koolhaas et al., 1999). Various behavioural models reflecting coping strategies exist for mammals, birds and teleosts (cichlids, salmonids, sticklebacks and a large number of tropical fish, reviewed in ( $\varnothing$ verli et al., 2007)). Individuals with divergent coping styles can be clustered into two main categories: proactive and reactive individuals. Proactive individuals tend to engage in active avoidance or cope with stressful stimuli (Koolhaas et al., 1999; Koolhaas, 2008) through a "fight or flight" response. Their behaviour differs from that of reactive individuals as follows: 1) they are more aggressive/dominant ( $\varnothing$ verli et al., 2004; Castanheira et al., 2013a), 2) they show greater motivation to feed after transfer to a novel environment ( $\varnothing$ verli et al., 2007), 3) they rapidly approach new objects (Castanheira et al., 2013b), 4) they take more risks (i.e. they are bolder) and are more likely to explore when exposed to novelty ( $\varnothing$ verli et al., 2006; MacKenzie et al., 2009; Martins et al., 2011a) and 5) they tend to develop behavioural routine (Bolhuis et al., 2004; Ruiz-Gomez et al., 2011). Physiologically, a proactive strategy is associated with lower hypothalamus-pituitary-inter-renal (HPI) activity (de Boer et al., 1990;

$\emptyset$ verli et al., 2005; $\emptyset$ verli et al., 2007; Silva et al., 2010) and higher sympathetic reactivity 
( $\varnothing$ verli et al., 2007) than in reactive individuals. Therefore, proactive animals typically have lower basal concentrations of glucocorticoids (the principal hormones involved in the stress response and the ultimate product of $\mathrm{HPI}$ axis activation) and lower stress-induced glucocorticoids concentrations ( $\varnothing$ verli et al., 2007) than reactive individuals. As individuals differ in their behavioural and physiological responses, they probably display differential adaptation to different types of environment.

An understanding of this individual variation is essential, to increase our knowledge of the adaptive value of behaviour (Wolf et al., 2007), which may affect individual fitness. Moreover, coping style has been shown to have implications in a wide range of fields (reviewed by Castanheira et al., 2013b) including behavioural ecology (Réale et al., 2007), neurosciences (Veenema et al., 2003), aquaculture (Huntingford and Adams, 2005), welfare ( $\varnothing$ verli et al., 2004), health and susceptibility to disease (Fevolden et al., 1993; Koolhaas, 2008), performance traits (Martins et al., 2011b) and interpretations of molecular responses (MacKenzie et al., 2009). In addition, several studies have demonstrated the existence of QTL associated with boldness and stress responses (Benus et al., 1991; Dingemanse et al., 2002; van Oers et al., 2004; Wright et al., 2006; Dingemanse et al., 2012; Rexroad et al., 2012), suggesting that it may be possible to select individuals on the basis of coping style.

Several methodological approaches have been used to characterise coping styles in fish. The methods used have included individual-based tests, such as confinement in rainbow trout (Oncorhynchus mykiss) ( $\varnothing$ verli et al., 2004; Øverli et al., 2007), recovery of feeding motivation in a novel environment in African catfish (Clarias gariepinus) (Martins et al., 2005) and rainbow trout ( $\varnothing$ verli et al., 2007), Senegalese sole (Solea senegalensis) (Silva et al., 2010) and Nile tilapia (Oreochromis niloticus) (Martins et al., 2011c), exposure to a novel 
object in Nile tilapia (Martins et al., 2011c), aggression tests in rainbow trout ( $\varnothing$ verli et al., 2007) and gilthead seabream (Sparus aurata) (Castanheira et al., 2013a), and restraint tests in Senegalese sole (Silva et al., 2010; Martins et al., 2011a) and gilthead seabream (Arends et al., 1999; Castanheira et al., 2013a). Most of these behavioural tests are carried out in isolation conditions, but the gregarious character of certain species, may influence behavioural responses and should be taken into account when interpreting data (reviewed by (Ashley, 2006). Some group-based tests have also been developed. Most of these tests concern risk-taking in European seabass (Dicentrarchus labrax) (Millot et al., 2009) or common carp (Cyprinus carpio) (Huntingford et al., 2010) and hypoxia exposure in rainbow trout (Laursen et al., 2011) and gilthead seabream (Castanheira et al., 2013b).

Most behavioural studies assessing the consistency of coping style over time are based on the use of different tests over a relatively short period (e.g. tests were repeated over one week by Budaev (1999) or two weeks by Castanheira et al. (2013b)). Analyses of the consistency of behavioural screening results between repeated tests or different challenges (cross-context analyses) are generally carried out over periods of one to eight days (Wilson and Stevens, 2005; Øverli et al., 2007; Wilson and Godin, 2009; Wilson et al., 2010). Few studies have investigated the repeatability of personality tests over both short and long intervals (see David et al., 2012). However, Bell et al. (2009) reported that repeatability was generally greater for experiments separated by short intervals than for those separated by longer intervals. This is not surprising, because several studies have indicated a role for various factors in shaping or influencing coping style. These factors include predation pressure (Brown and Braithwaite, 2004; Brown, 2005; Archard and Braithwaite, 2011; Archard et al., 2012), the predictability of food supply (Chapman et al. 2010) and food 
density (Dunbrack et al., 1996), social interactions (Chapman et al., 2008), temperature or hypoxia (Biro et al., 2010), learning (Millot et al., 2009), environment stability (Brelin et al., 2008) and stress (Ruiz-Gomez et al., 2008). Stamps and Groothuis, (2010) pointed out that behavioural tendencies that are consistent over short periods of time are likely to change over longer periods. Researchers must therefore consider carefully the observation intervals most appropriate for their focus species and for the questions addressed. We therefore decided to use a life history approach in our species of interest, seabass, a marine fish of particularly high commercial value, with a current mean European production of about 125,000 metric tons year ${ }^{-1}$ (Tveteras and Nystoyl, 2011).

The aim of this study was to assess individual coping style through the use of various individual-based and group-based tests, adding a life history approach to data interpretation. The chosen approach was the screening of individually tagged fish in repeated (at least twice) tests over a long period (629 days, from 129 to 758 days post hatching, dph), with the use of various intervals between tests. The aims were: (i) to assess behavioural and physiological consistency over time, and (ii) to define the most appropriate test for the characterisation of coping style in seabass, and (iii) the most appropriate time interval between tests if repetition is needed. This approach made it possible to assess various aspects of individual behavioural consistency and to evaluate age and life experience effects. By using different tests, we were also able to analyse responses to different situations ("cross-context" analyses, Wilson et al. 2010). We adapted and developed screening methods for this particular purpose. The overall objective was to improve our understanding of seabass individual adaptation capacity, given that there is currently little or no domestication of this species. Indeed the use of coping style characterization could represent new keys for the sustainable development of aquaculture, in enhancing animal 
welfare, reducing disease susceptibility, and more directly improving production performances. It could also be an additional tool to improve the domestication process, selecting individuals better adapted to farming conditions (i.e. broodstock), but also showing higher growth performances.

\section{MATERIALS \& METHODS}

\subsection{Fish and experimental conditions}

A batch of 200 juvenile seabass ( $87 \mathrm{dph}$, industrial strain), with an initial body weight of $0.5 \pm 0.2 \mathrm{~g}$ (mean $\pm \mathrm{SEM}$ ) were bought from Aquastream (Ploemeur, 56, France) and transferred to the laboratory on $01 / 11 / 2011$. The animals were allowed to acclimate to the conditions and were then placed in one of six 400 -litre tanks in the experimental room at the Fish Ecophysiology Platform in La Rochelle (http://wwz.ifremer.fr/pep, France).

Water was recirculated in these tanks with a flow rate of $4 \mathrm{~m}^{3} \mathrm{~h}^{-1}$, with $15 \%$ renewal per day. Tanks were protected by an opaque black curtain, to prevent disturbance. Each tank was illuminated by an overhead white light (Philips, 80W). The light cycle was controlled (13 hours day/ 11 hours night) and the same photoperiod was used for all experimental procedures. Sunrise and sunset were each simulated by a 30 -minute twilight transition period, consisting of six steps of increasing or decreasing luminosity, regulated automatically by computer-driven potentiometers. Water temperature, oxygen saturation and salinity were monitored daily, to ensure that conditions were optimal: water temperature was maintained at $20.1 \pm 1.7^{\circ} \mathrm{C}$, oxygen saturation at $75.2 \pm 0.9 \%$ and salinity at $26.9 \pm 0.9$. Concentrations of nitrites, nitrates and ammonium were checked weekly (JBL kit) and the mean results were as follows: $\mathrm{NO}_{2} \quad 0.13 \pm 0.06 \mathrm{mgl}^{-1} ; \quad \mathrm{NO}_{3} \quad 0.97 \pm 0.11 \mathrm{mg} \mathrm{I}^{-1}$; $\mathrm{NH}_{4}<0.05 \mathrm{mg} \mathrm{l}^{-1}$. 
159

160

161

162

163

164

165

166

167

168

169

170

171

172

173

174

175

176

177

178

179

180

Fish were hand-fed each day with specialised commercial food (61\% proteins, 33\% lipids), according to the quantity/weight table provided by the supplier (INICIOplus, BIOMAR ${ }^{\circledR}$, France).

One week after their arrival, we determined the weights and lengths of a subsample of 30 fish, which were then placed in a similar tank in the same room for further analyses to assess coping style. These individuals were tagged under anaesthesia with RFID glass microtags (Nonatec $^{\circledR}$, as described by Cousin et al., 2012 and Ferrari et al., 2014) at $115 \mathrm{dph}(1.6 \pm$ $0.26 \mathrm{~g})$, two weeks before the start of the experimental procedure. They were doubletagged at $180 \mathrm{dph}(8.45 \pm 1.39 \mathrm{~g})$, with a conventional ISO PIT Tag, to prevent a loss of identification due to the short distances over which Nonatec ${ }^{\circledR}$ microtags can be detected.

We assessed the coping styles of the fish in the subsample from $129 \mathrm{dph}(2.56 \pm 0.55 \mathrm{~g})$ to $630 \mathrm{dph}(639.35 \pm 134.43 \mathrm{~g}$ ), as shown in Table 1. Each fish was subjected to a series of different tests: individual-based tests such as feeding recovery in a novel environment (adapted from ( $\varnothing$ verli et al., 2007), aggression tests (adapted from $\varnothing$ verli et al., 2007), exploration tests in a T-maze (adapted from (Ninkovic and Bally-Cuif, 2006), restraint in a net (adapted from Arends et al., 1999; Silva et al., 2010 and Martins et al., 2011a); and groupbased tests such as risk-taking (adapted from Millot et al., 2009) and hypoxia exposure (adapted from Laursen et al., 2011) tests.

\section{$\underline{2.2 \text { Individual-based tests }}$}

\subsubsection{Feeding recovery test (test 1)}

Three sessions were carried out, to evaluate the consistency of feeding recovery in isolation. For the first session (test 1-1, Table 1), fish were measured and similar fish were paired $(<10$ 
$\%$ difference in weight), because an aggression test was carried out immediately after the feeding recovery test (test 2 , Table 1 ). The two fish of each pair were placed in two equal compartments of an isolation aquarium $\left(\mathrm{I}^{*} \mathrm{w} * \mathrm{~h}: 21.2 * 26.7 * 15 \mathrm{~cm}, 8.5 \mathrm{I}\right)$ separated by a removable opaque PVC divider to prevent visual contact. The fish were hand-fed ad libitum two hours after transfer to isolation conditions and then once daily (between 12:00 and 14:00, and with the same commercial pellets described above), for two minutes, or until the fish rejected three consecutive pellets. Individual feeding behaviour was carefully observed on each occasion. Food that had not been consumed was removed by siphoning with a transparent plastic hose. Feeding recovery behaviour was assessed in detail by considering the following variables of interest: feeding score, time to feeding and total number of feeding days. Feeding score was rated on a four-point scale, according to the criteria listed in Table 1 in $\varnothing$ verli et al. (2007), and daily scores obtained over a one-week period were then summed for each individual. Briefly, if the fish did not respond to the food, it was attributed a score of 0 ; if the fish ate only pellets falling directly in front of it without moving to take food, the score was 1 ; if the fish moved more than one body length to take food, but returned to its original position in the aquarium between food items, the score was 2 and, finally, if the fish moved continuously between food items and consumed all the food presented, the score was 3. For each fish, feeding latency (in days), corresponding to the time until the first pellets were consumed during the experiment, was used as a quantitative measurement of the recovery of feeding behaviour in a new environment. Total number of feeding days was determined as the number of days on which the fish ate at least one pellet.

This test was repeated three times (three sessions) on the same group of individuals: session 1 at 129 dph, session 2 at 283 dph (5 months later, test 1-2, Table 1) and session 3 at 548 dph (another 9 months later, test 1-3,Table 1). The volume of the aquarium was adjusted for 
fish body size, i.e.: I* $w^{*} \mathrm{~h}: 40 * 20 * 25 \mathrm{~cm}, 20$ I for session 2 and $60 * 25 * 35 \mathrm{~cm}, 52.5 \mathrm{I}$ for session 3, without no divider for sessions 2 and 3 because no subsequent aggression test was carried out during these sessions (see next section).

\subsubsection{Aggression test (test 2)}

In the aggression test, each fish was provided with the opportunity to interact with another fish of similar size (maximum $10 \%$ weight difference). After one week in isolation (Test 1-1, Table 1), pairs of fish were individually gently netted and placed into the behaviour observation room (in four tanks: cage type 3, Bioscape Gmbh, Germany; $42.3 * 26.5 * 15 \mathrm{~cm}$, $7.5 \mathrm{~cm}$ water depth, $8.4 \mathrm{I})$. Each tank was separated into two equal compartments by an opaque PVC divider. The whole set-up was installed on an infrared floor (IR floor $1 \times 1 \mathrm{~m}$, Noldus, the Netherlands) to prevent light reflection. After $24 \mathrm{~h}$ of acclimation, the dividers were removed and interactions were video-recorded at 25 frames per second (Ethovision XT recording, Noldus, the Netherlands; Ikegami CD48E camera; 2.8 - 12 mm Computar $^{\circledR}$ lens equipped with an IR filter) for 60 minutes or until the dominant fish was clearly identified. The variables of interest were: chasing latency (i.e. the time in seconds until the first chase, defined as a sudden change in swimming direction and speed in response to an approach by the opponent), the number of chases, fight latency (i.e. the time in seconds until the first fight, defined as the fish making circular carousel-type movements around each other), and the number of fights (adapted from (Reyes-Tomassini, 2009).

This test was carried out only once, at $137 \mathrm{dph}$.

\subsubsection{Exploratory test in a T-maze (test 3)}


Fish were placed individually in a T-maze $(100 * 20 \mathrm{~cm}$, with a water depth of $15 \mathrm{~cm}$, Figure 1). The whole set-up was placed on an infrared floor (as above) to prevent light reflection. The fish were allowed to recover for five minutes in the start box, and we then videorecorded 15 minutes of exploration behaviour at 25 frames per second (Ethovision XT recording, Noldus, the Netherlands; Ikegami CD48E camera; 2.8 - 12 mm Computar $^{\circledR}$ lens equipped with an IR filter). With the software used, we were able to separate the maze into three virtual zones: the start box zone, the open zone and the safe zone (end of one arm with a cover creating a shadowed area, Figure 1). The variables of interest were: time to entry into the open zone (s), total time spent in the open zone (s), total time spent in the safe zone (s) and the distance covered (expressed in body length. $s^{-1}$ ). Fish escaping directly from the start box when the door was opened were removed from analyses. Indeed, the start box was considered a safe area at the end of the five-minute recovery period. Thus, any fish escaping immediately from the start box when the door was opened were considered to have been frightened by human disturbance, such fear generally resulting in higher swimming velocity, greater exploration of the maze and a longer time spent in the open zone than for other fish. Such behaviour cannot be considered "normal".

This test was repeated twice, 161 days apart (tests 3-1 at $150 \mathrm{dph}$ and 3-2 at $311 \mathrm{dph}$, Table 1).

\subsubsection{Restraint test (test 4)}

In the net restraint test, each fish was held individually in a net, out of water, for three minutes (adapted from Arends et al., 1999; Silva et al., 2010; Martins et al., 2011b). While the fish was in the net, the following variables were measured: escape latency (i.e. the time in seconds to the first escape attempt, defined as an elevation of the body in the net, a 
249 jump); the total number of escape attempts and the total time (s) spent in trying to escape

250 (i.e. the sum of the durations of all escape attempts).

251 This test was repeated three times, in session 1 at $557 \mathrm{dph}$, session 2 at $739 \mathrm{dph}$ and session

2523 at 758 dph (tests $4-1,4-2$ and $4-3$ respectively, Table 1 )

253

254

255

256

257

258

259

260

261

262

263

264

265

266

267

268

269

270

\section{$\underline{2.3 \text { Group-based tests }}$}

\subsubsection{Risk-taking test (test 5)}

We evaluated risk-taking behaviour, by separating the tank (identical to rearing tank, $400 \mathrm{I}$ ) into two unequal zones with an opaque divider. The safe zone was shadowed, accounted for two thirds of the available space and contained all the fish at the start of the experiment.

The other zone, the risky zone, was lit and accounted for the remaining one third of the space available. The opaque divider had a circular $(12 \mathrm{~cm} \emptyset)$ opening at its centre, which was equipped with a PIT-tag detection antenna connected to a control device (adapted from Millot et al., 2009). This set-up made it possible to monitor individual passages through the opaque divider, which were attributed to a particular time point. Three tests were carried out, at 15-day intervals, starting at $187 \mathrm{dph}$ (tests 5-1, 5-2 and 5-3, Table 1). Environmental conditions were kept constant for all three tests. The same procedure was used each time and the test lasted $24 \mathrm{~h}$. The divider was installed in the tank at 11:30, and the opening was blocked for 30 minutes before the start of the test. The variables of interest for these tests were: the order in which individuals passed for the first time from the safe to the risky area, the total number of passages through the opaque divider for each individual, used as a proxy of activity during the test, and time ( $\mathrm{min}$ ) to the first passage into the risky zone for each individual. 


\subsubsection{Hypoxia test (test 6)}

272 In the hypoxia test, we decreased the oxygen concentration in one of the chambers of a two-

273 chamber tank and assessed escape from the hypoxic to the normoxic compartment. The experiments were carried out with two identical circular tanks (70 I, h: $48 \mathrm{~cm}$, diameter: 49.5 $\mathrm{cm}$, ) attached to each another via a transparent acrylic pipe (diameter: $11 \mathrm{~cm}$, length: $30 \mathrm{~cm}$, height from bottom: $23 \mathrm{~cm}$ ) equipped on each side with a PIT-tag detection antenna connected to a control device for further analyses (see Castanheira et al., (2013b) for a detailed diagram of the apparatus). Each tank was considered to be a separate environment individually equipped with an oxygen and air supply, which was switched off during the trials in the hypoxia tank (see below). All the fish were placed in one chamber of the tank (which subsequently became the hypoxia tank) and were allowed to acclimate to the conditions for 30 minutes before the start of the experiment. The hypoxia tank was supplied with nitrogen, to induce hypoxic conditions during the experiment (nitrogen bubbling to decrease oxygen saturation from $90 \%$ to $8 \%$ in 1 hour). The second chamber of the tank, which was supplied with oxygen, is referred to as the normoxia tank. The variables of interest were: time taken to escape the hypoxia tank (i.e., the time $(\mathrm{min})$ taken by each fish to escape from the hypoxia tank to the normoxia tank), the order in which individual fish escaped the hypoxia tank, the oxygen level in the hypoxia tank when the fish first passed into the normoxia tank (\% saturation) and the number of returns to the hypoxia tank. The hypoxia test ended when two thirds of the fish had escaped from the hypoxia tank or when $8 \%$ oxygen saturation was reached (water temperature $20^{\circ} \mathrm{C}$, salinity 26.9). Once an individual escaped from the hypoxic tank into the normoxia tank, it was considered to be a hypoxia avoider (HA), regardless of the number of times it subsequently returned to the hypoxia tank, whereas fish remaining in the hypoxia tank were considered to be hypoxia-tolerant (HT). Controls 
experiments were performed three times ( $3 * 60$ individuals), using the same set-up but without hypoxia induction. The test was performed twice, during session 1 at $457 \mathrm{dph}$ and session 2 at 502 dph (tests 6-1 and 6-2 respectively, Table 1).

\subsection{Physiological measurements}

Physiological measurements were carried out after feeding recovery session 2 (when the fish had grown sufficiently for blood sampling to be feasible), hypoxia test session 1 and restraint test session 1, to enable us to link plasma cortisol concentrations and behavioural responses.

Immediately after the final observation period of feeding recovery test session 2 (test 1-2, $290 \mathrm{dph}$ ), the fish were anaesthetised in the isolation tank. Care was taken to ensure that the fish could not see the researcher. Blood samples were then taken from the fish, for the evaluation of cortisol levels in undisturbed conditions and fish were taken back to their home tank after waking up. At the end of the hypoxia test (test 6-1, $457 \mathrm{dph}$ ), blood samples were collected from the anaesthetised fish in the two experimental tanks (normoxia and hypoxia), the values obtained being considered to correspond to cortisol concentrations after acute stress. Fish were taken back to their home tank after waking up. Finally, as described by Arends et al. (1999), fish were individually isolated in an aquarium $(60 * 25 * 35$ $\mathrm{cm}$ ) for 30 minutes after the net restraint test (test 4-1, $557 \mathrm{dph}$ ). They were then quickly removed from the tank and anaesthetised for blood sampling; hereafter fish were taken back to their home tank after waking up. The individual plasma cortisol concentrations measured in undisturbed conditions (test 1-2) were compared with those obtained after acute stress (tests 4-1, 6-1).

The same blood sampling procedure was used in each case: fish were anaesthetised with $325 \mu \mathrm{l} \mathrm{L}^{-1}$ of a stock solution of benzocaine (a $10 \%$ stock solution of ethyl-p-aminobenzoate- 
E1501, from Sigma, St Louis, MO, USA, was prepared by dissolving $100 \mathrm{~g}$ in $1 \mathrm{I}$ of $100 \%$ ethanol), and blood samples were obtained within 3 minutes, from the caudal vein, with heparinised syringes. The blood was centrifuged ( $5 \mathrm{~min}$ at $3500 \mathrm{~g}$ ) to obtain plasma samples, which were stored at $-22^{\circ} \mathrm{C}$. Plasma cortisol concentration was determined with an ELISA kit (RE52061, IBL, Germany). All other fish manipulations, such as weighing and length measurements, were performed under the same conditions of anaesthesia. The number of fish used in behavioural tests differed in some cases from the number of fish for which plasma cortisol concentrations were obtained, because technical problems prevented the analysis of some blood samples.

After all experiments were finished, fish were killed with an overdose of anaesthetic and phenotypic sex was determined according to the method described by (Barnabé, 1976, in Ferrari et al. 2014).

\subsection{Individual stability}

Consistency refers to the predictability of repeated measurements of behaviour in a group of individuals, whereas stability refers to within-individual repeatability of behaviour (Nunnally, 1967; Sih et al., 2004). Several indices are available for estimating the stability of behaviour within an individual. We calculated the coefficient of relative plasticity (CRP) for each individual, as described by Réale and Dingemanse (2010), as the ratio of individual trait variance $(\mathrm{Vi})$ to the overall phenotypic variance $(\mathrm{Vp})$ of the population: $\mathrm{CRPi}=\mathrm{Vi} / \mathrm{Vp}$. CRP provides a standardised index of the variation of a given trait within a focal individual, relative to its population.

\subsection{Data analysis}


341 We carried out Shapiro-Wilk tests to check that the data were normally distributed and

342 Bartlett's test to check for variance homogeneity. We calculated the mean and standard 343 deviation (SD), to assess the variability of behavioural responses. For each variable of 344 interest, inter-individual variability was assessed by calculating the coefficient of variation $345(\mathrm{CV}=\mathrm{SD} / \mathrm{mean} * 100, \%)$ as a normalised measure of dispersion. For each behavioural test, 346 we assessed the correlation between the values of each variable of interest between 347 individuals. The variables of interest in each test were then collapsed into first principal component scores (PC1, this method provided one value per individual on the PC1 axis) by 349 principal component analysis (PCA).

We analysed the consistency of behaviour, by assessing the correlation between the PC1s of sessions 1 and 2. Pearson's correlation tests were carried out for normally distributed data, whereas Spearman's rank correlation tests were carried out for data that were not normally distributed. For analyses of cross-context consistency, the PC1s of sessions 1 and 2 were averaged for each test, and the correlation between tests was analysed using Spearman tests with $\mathrm{N}=24$ individuals (the smallest sample size) and $\alpha=0.05$ corrected using Bonferroni method with $n=5$ tests, the threshold for significance is $r_{s(N=24, \alpha=0.01)}>0.476(p 793$, in Scherrer 1984) .

A non-parametric test, the Mann-Whitney $U$ test, was used to analyse differences in plasma cortisol concentrations between HA and HT fish in the hypoxia test. The repeatability of relative plasticity (CRP) was assessed for each individual, as described by Nagawama and Schielzeth (2010), with GLMMs in the Ime4 package for R (Development Core Team, 2005). One model (Mod1) including individual identity and a false identity variable with the same value for each individual 
364

365

366

367

368

369

370

371

372

373

374

375

376

377

378

379

380

381

382

383

384

385

glmer(CRP Behaviour+(1| Individuals)+(1|False)) was compared with another model without individual identity as a variable (Mod $2<-$ glmer(CRP Comportement+(1|False)). The Akaike information criterion (AIC) was calculated for each model and compared between models in likelihood ratio test (LRT) analyses of variances (ANOVA). Other statistical analyses were performed with Statistica for windows (Statsoft, USA), and values of $p<0.05$ were considered significant in all tests.

\section{RESULTS}

\subsection{Individual variation}

An analysis of coefficients of variation (min: 12.9\%; max: $401.8 \%$ ) revealed considerable inter-individual variability in the variables measured in the various tests carried out (Table 2). This suggests that there was a high level of behavioural plasticity in this group of fish, given that experimental conditions were otherwise equal.

\subsection{Individual consistency of behavioural and physiological responses over time and} contexts

\section{Individual-based tests}

\subsubsection{Feeding recovery test (test 1)}

In the first session, feeding activity recovered over several days, as illustrated by the increase in the frequency of a score of 3 during the course of the week (Figure 2A). Feeding recovery scores were lower during session 2 (Figure 2B), and almost no feeding recovery was observed in session 3 (Figure 2C), when the fish were at their oldest (548 dph) and displayed thigmotaxic behaviour (remaining close to one corner of the tank), avoiding pellet ingestion or moving towards the experimenter (visual observations). Feeding latency increased 
386

387

between sessions 1 and 2, from 2.2 days to 3.3 days, and reached 6.7 days in session 3 (Table 2). No individual correlation between the three sessions was found for these two variables. However, a significant positive correlation was found between the total number of feeding days of sessions 1 and $2\left(r_{s}=0.39 ; p=0.04\right)$ for individuals, whereas no such correlation was observed between sessions 1 and $3\left(r_{s}=0.08 ; p=0.74\right)$ or sessions 2 and $3\left(r_{s}=0.26 ; p=0.24\right)$. Principal component analysis (PC1 scores) revealed an absence of consistency: no correlation was found between the PC1s for sessions 1 and $2\left(r_{s}=0.33 ; p=0.09\right)$, sessions 1 and $3\left(r_{s}=0.05 ; p=0.83\right)$ or sessions 2 and $3\left(r_{s}=0.12 ; p=0.59\right)$, although PC1s axes explained 84.8 to $97.2 \%$ of the variability of the dataset (table 3 ).

\subsubsection{Aggression test (test 2)}

When the divider was removed for studies of dominance-subordination interactions, the fish encountered each other and swam side by side. Aggressive interactions were observed for only one of the 12 pairs of fish tested, (107 chases by the dominant fish), beginning after 10.1 minutes. Given the lack of aggressive interactions observed in this initial test, it was not repeated during subsequent sessions and was not analysed further.

\subsubsection{Exploratory test in a T-maze (test 3)}

In total, 25 fish were tested in both sessions 1 and 2, but eight of the fish tested in session 2 were removed from the analysis due to abnormal behaviour (see Methods section). The fish spent almost 40 times longer in the open zone in session 2 than in session 1, spending only half as long in the safe zone and covering a distance five times longer than that in session 1 (Table 2). No correlation was found between sessions 1 and 2 for the individual values of any of the variables measured. The PC1s on session 1 and 2 explained respectively 38.1 and 
408

409

410

411

412

413

414

415

416

417

418

419

420

421

422

423

424

425

426

427

428

429

$46.1 \%$ of the dataset (table 3). PC1 correlation analysis revealed an absence of consistency in exploratory behaviour between sessions 1 and $2\left(r_{s}=0.08, p=0.79\right)$.

\subsubsection{Restraint test (test 4)}

Time to first escape attempt (escape latency) was four times longer in session 2 than in session 1 (Table 2), whereas the number of attempts to escape from the net decreased significantly over the course of the three sessions (Friedman ANOVA, Chi ${ }^{2}=28.35 ; p<0.001$ ), from 37.1 in session 1 to 15.5 in session 2 and 4.4 attempts in session 3 (Figure 3). No individual correlation was observed for any of the variables tested. For individuals, PC1 correlation analysis revealed an absence of consistency between sessions 1 and $2\left(r_{s}=0.19\right.$; $p=0.39)$, sessions 2 and $3\left(r_{s}=-0.06 ; p=0.8\right)$ and sessions 1 and $3\left(r_{s}=0.36 ; p=0.15\right)$. The PC1s on session 1, 2 and 3 explained respectively $60.1,63.1$ and $63.8 \%$ of the dataset (table 3 ).

\section{$\underline{\text { Group-based tests }}$}

\subsubsection{Risk-taking test (test 5)}

Time to first passage into the risky zone decreased strongly between sessions 1 and 2, from 568.7 to 96.0 minutes (Table 2). By contrast, the number of returns into the safe zone was three times higher in session 2 than in session 1 (86 in session 1 and 289 in session 2; Table 2). The order in which the fish escaped was not correlated between sessions 1 and $2\left(r_{s}=\right.$ $0.22 ; \mathrm{p}=0.22)$, sessions 1 and $3\left(r_{s}=0.11 ; p=0.52\right)$ or sessions 2 and $3\left(r_{s}=0.25 ; p=0.17\right)$. Nevertheless, risk-taking test results were consistent in terms of individual activity (evaluated by considering the number of passages/2 to be the number of returns to the safe zone). Indeed, individual values were significantly correlated between sessions 1 and 2 ( $r_{s}$ 
$=0.49 ; p=0.006$; Figure $4 A$ ), and even more strongly correlated between sessions 2 and 3

$\left(r_{s}=0.72 ; p<0.001 ;\right.$ Figure 4B), whereas only a trend was observed between sessions 1 and 3

$\left(r_{s}=0.33 ; p=0.06\right.$, not shown). In addition, the order in which the fish escaped was correlated

with the number of returns to the safe zone of individual fish in sessions 1 and 2 (session 1 :

$r_{s}=-0.54, p=0.002$, Figure $5 A$; session $2: r_{s}=-0.67, p<0.001$, Figure $\left.5 B\right)$, but not in session 3

$\left(r_{s}=-0.28 ; p=0.13\right.$, data not shown). The PC1s on session 1,2 and 3 explained respectively

72.8, 66.1 and $52.4 \%$ of the dataset (table 3).The PC1s for sessions 1 and 2 were correlated

$\left(r_{s}=0.51, p=0.003\right.$, Figure $\left.6 A\right)$, as were those for sessions 2 and $3\left(r_{s}=0.53 ; p=0.002\right.$; Figure

$6 B)$, but no correlation was found between the PC1s of sessions 1 and $3\left(r_{s}=0.32, p=0.08\right.$,

data not shown) hereby showing consistency in individual consistency.

\subsubsection{Hypoxia test (test 6)}

In the three control tests, only three fish passed through the opening, confirming the

necessity of hypoxia induction to trigger the movement of the fish from the hypoxia tank to the normoxia tank and validating the test protocol. There were four times as many returns to the hypoxia tank in session 2 than in session 1 (5.22 versus 1.29; Table 2). The mean time to first passage into the normoxia tank remained stable over time, at 38.7 minutes in session 1 and 43.2 minutes in session 2 (Table 2). Hypoxia tolerance in session 1 was positively

447 correlated with the individual number of returns in session $2\left(r_{s}=0.69 ; p<0.001\right.$, data not shown). The order in which individuals escaped was positively correlated between sessions 1 and $2\left(r_{s}=0.78 ; p<0.001\right)$. The PC1s on session 1 and 2 explained respectively 75.4 and $81.9 \%$ of the dataset (table 3). A strong positive correlation was found between the PC1s for sessions 1 and $2\left(r_{s}=0.65 ; p<0.001 ;\right.$ Figure 7$)$ showing a high consistency in individual response. 


\subsection{Link between behavioural and physiological measurements}

455

456

457

458

459

460

461

462

463

464

465

466

467

468

469

470

471

472

473

474

At the end of the feeding recovery test (session 2), mean plasma cortisol concentration was $244.96 \pm 197.72 \mathrm{ng} \cdot \mathrm{ml}^{-1}$, with a CV of $80.72 \%$ indicating a high level of variability in the population. No correlation was found between this variable and the PC1 for the feeding recovery test $\left(r_{s}=0.40 ; p=0.14\right)$.

Thirty minutes after the restraint test (session 1), cortisol concentration was $509.27 \pm 135.11 \mathrm{ng} \cdot \mathrm{ml}^{-1}$, with a CV of $26.53 \%$, and was not correlated with the PC1 for the net restraint test $\left(r_{s}=-0.32 ; p=0.19\right)$. By contrast, it was significantly negatively correlated with the individual number of escape attempts $\left(r_{s}=-0.54 ; p=0.02\right.$; Figure $\left.8 \mathrm{~A}\right)$. No correlation was found for the other variables (escape latency: $r_{s}=-0.29 ; p=0.19$; and total escape duration: $\left.r_{s}=-0.13 ; p=0.55\right)$.

After the hypoxia test (session 1), mean cortisol concentration was similar to that after restraint, at $501.42 \pm 110.57 \mathrm{ng} \cdot \mathrm{ml}^{-1}$, and was not correlated with the PC1 for the hypoxia test $\left(r_{s}=-0.36 ; p=0.2\right)$. However, it was significantly negatively correlated with individual oxygen level at the first passage (Figure $8 B ; r_{s}=-0.73 ; p=0.002$ ). No correlation was found with the number of returns, time to first passage or escape order, but differences were identified between the HA and HT groups $\left(449.9 \pm 106.2\right.$ and $560.3 \pm 88.2 \mathrm{ng} \cdot \mathrm{ml}^{-1}$, respectively; MWU, HA vs. HT, Z=2.08; $\mathrm{p}=0.04)$.

Furthermore, a significant negative correlation was found between the plasma cortisol concentrations obtained after the feeding recovery test and after the net restraint test $\left(r_{s}=-\right.$ $0.52 ; p=0.046)$. 


\subsection{Cross-context consistency}

477 Cross-context consistency was analysed by determining the mean PC1 for sessions 1 and 2

478 for each test and comparing these mean PC1 values between the different behavioural tests.

479 No correlation was found between the PC1 values of any of the tests considered (Table 4).

\subsection{Individual stability}

482

483

484

485

486

487

488

489

490

491

492

493

494

Sex had no effect on mean CRP (MWU, Z=1.44; $p=0.16$ ), and no difference was found between the two GLMM models tested (Mod1: $A I C=271.53$ and Mod2: $A I C=269.53 ; p=1$ ). Within-individual CRP was no smaller than between-individual CRP. CRPs were not repeatable and were context-specific (Table 5).

\section{DISCUSSION}

This study provides a first insight into the characterisation of coping style in European seabass through the use of individual- and group-based tests, and an assessment of the short- and long-term consistency of behavioural responses.

\subsection{Individual- vs. group-based tests in seabass}

One of the key findings of this study is the much lower level of individual responses consistency over time observed for the results of tests done in isolated situation (feeding recovery, exploration and restraint) than for those of group-based tests. This may be due to 
495

496

497

498

499

500

501

502

503

504

505

506

507

508

509

510

511

512

513

514

515

516

517

a number of factors, including fish age, learning capacity and species-specific features, such as the gregarious nature of juvenile seabass, gradually replaced by a preference for solitude in adults (Barnabé, 1980; Bas Peired, 2002).

The results obtained for the feeding recovery test in the first session were similar to those obtained for rainbow trout by $\varnothing$ verli et al. $(2006,2007)$, with a gradual recovery of feeding activity after a period of little or no activity during the first two or three days. However, no consistency over time was observed when this test was repeated. This may have been due to too long a period being left between sessions (i.e. 154 days and 265 days ), but similar conclusions were reached in the study of gilthead seabream by Castanheira et al. (2013b), in which the interval between tests was only 15 days. Alternatively, the difference in results between the two sessions may be due to changes in fish metabolic rate with age/size. Indeed, young fish have higher metabolic needs than older fish, due to investment in growth (reviewed by Oikawa and Itazawa, 1985), leading them to feed even in isolation. By contrast, older fish have a higher body weight and could fast for longer periods of time, enabling them to avoid eating pellets in front of the experimenter. The use of feeding recovery tests to study behaviour consistency in seabass would therefore be difficult. Furthermore, the results of this test were not predictive of cortisol profile in individual fish, precluding further interpretation.

For the exploration test, the results might be accounted for by the interval between sessions 1 and 2 being too long (161 days). However, they may also be due to a technical problem, in that the T-maze is mostly used to test learning rather than exploration per se. The use of another type of maze, such as the Z-maze (Chapman et al. 2010), or an open field system with a shelter, would have been more relevant, as shown by Ferrari et al. (2014b). 
518 Finally, in the restraint test, the decrease in the number of attempts to escape from the net

519 between sessions may be accounted for by the ageing of the fish, because session 2 was

520 performed 181 days after session 1 . However, even with a shorter time interval between

521 sessions (19 days between sessions 2 and 3), similar to that used by Castanheira et al.

522 (2013b), we found no consistency. Castanheira et al. (2013b) observed an increase in the

523 number of escape attempts and a high consistency between tests in gilthead seabream,

524 whereas we observed the opposite pattern in seabass, whatever the time interval.

525 All these results may also be accounted for by species specificity in behavioural responses. In

526 Nile tilapia (Martins et al., 2011b) and rainbow trout ( $\varnothing$ verli et al., 2006; Øverli et al., 2007)

527 for example, feeding recovery studies have shown that proactive individuals recover more

528 rapidly than reactive individuals, conflicting with the results obtained in the studies of

529 gilthead seabream by Castanheira et al. (2013b) and those for HR and LR F5 generation in

530 rainbow trout obtained by (LeBlanc $S$ et al., 2012). Indeed, the way in which individuals

531 respond to various stressors may have many consequences, which are usually context-

532 specific (Brown et al., 2007). In seabass, cortisol concentration 30 minutes after the restraint

533 test was negatively correlated with the number of escape attempts for a given individual.

534 This finding is in line with coping style theory: individuals with passive responses (reactive)

535 have higher blood cortisol levels after stress than those with an active response (proactive).

536 Our restraint test results are consistent with those of David et al., (2012) on a passerine

537 (zebra finch, Taeniopygia guttata), showing a decrease in escape behaviour (called

538 "struggling rate" in their experiment) over sessions and a lack of correlation between

539 sessions. However, they conflict with those of Castanheira et al. (2013b) for gilthead

540 seabream, showing an increase in the number of escape attempts by individuals and a

541 correlation between sessions 1 and 2 but no correlation with cortisol levels. All together, 
542 these findings provide evidence for a high degree of species specificity in the behavioural

543 responses observed during restraint tests. Interestingly, the plasma cortisol concentrations

544 obtained 30 minutes after the net restraint test were negatively correlated with those

545 obtained after one week of feeding recovery in isolation. Thus, fish with high cortisol levels

546 after an acute stress (reactive) had low cortisol levels after a chronic stress. The kinetics of

547 cortisol responses therefore seem to differ with coping style and between tests.

548 Another explanation for the lack of consistency over time in the results obtained for 549 individual-based tests may be the susceptibility of seabass to stress. Indeed, juvenile seabass

550 are known to be gregarious, and social isolation may therefore be highly stressful in this 551 species (Ashley, 2006). As shown by Fanouraki et al., (2011), seabass may display plasma 552 cortisol concentrations of more than $750 \mathrm{ng} \cdot \mathrm{ml}^{-1}$ in response to acute stress, whereas these 553 concentrations are generally around $300 \mathrm{ng} \cdot \mathrm{ml}^{-1}$ for sharp snout seabream (Diplodus 554 puntazzo) and gilthead seabream, and less than $50 \mathrm{ng} \cdot \mathrm{ml}^{-1}$ for common dentex (Dentex 555 dentex) and meagre (Argyrosomus regius). Furthermore, Rotllant et al., (2003) showed in 556 their review that plasma cortisol concentration is higher in undisturbed seabass than in 557 other teleosts, such as salmonids and sparids (usually below $10 \mathrm{ng} \mathrm{ml}^{-1}$ ). Finally, Gregory and 558 Wood, (1999) and Øverli et al. (2002) showed that appetite may be inhibited by cortisol, 559 potentially accounting for the lack of feeding recovery observed here in older seabass after 560 their transfer into isolation conditions. In conclusion, isolation appears to be a stronger 561 stressor than the other challenges used here in seabass, thereby acting as a masking factor 562 in the tests used. 
564

565

566

567

568

569

570

571

572

573

574

575

576

577

578

579

580

581

582

583

584

585

586

587

By contrast to the individual-based tests, all the group-based tests performed in this study gave results that were highly consistent over time.

Our results for risk-taking behaviour confirmed those obtained by Millot et al. (2009) for seabass and by Huntingford et al. (2010) for carp. The fish found to take risks were the same in the various sessions and these fish were more active than those that did not take risks, despite differences in escape order. Further, high learning (defined as a change in behaviour with experience; Dill, 1983) and memory abilities were observed in these tests. The escape order in the first session can be considered to correspond to risk-taking behaviour, but such an assumption does not hold for the second session, as several studies have shown that the intensity of fear decreases as the animal masters the correct response (reviewed by Millot et al., 2009). These findings indicate that seabass can remember events over periods of at least 15 days (memory for more than one month was demonstrated by Millot et al., 2009). Furthermore, individual activity levels were highly consistent over time, and this is considered to be a strong axis of personality (Réale et al., 2007). Activity level (high activity being characteristic of proactive fish) and metabolic rates are also usually correlated, as demonstrated in seabass (Killen et al., 2011) and other species (Nespolo and Franco, 2007; Careau et al., 2008; Martins et al., 2011a; Herrera et al., 2014). Proactive and reactive individuals differ in terms of their metabolism. The higher metabolic rate of proactive seabass may therefore account for their higher level of activity and their more rapid exploration of new, potentially risky areas than reactive individuals. Similar results have also been reported for seabream (Herrera et al. 2014), in which the time to risk-taking was found to be negatively correlated with both movement and oxygen consumption rates. Riskavoiders (long times to risk-taking) were thus less active and consumed less oxygen than risk-takers. 
588

589

590

591

592

593

594

595

596

597

598

599

600

601

602

603

604

605

606

607

608

609

610

611

In the hypoxia test, the individuals showing the lowest tolerance to hypoxia and highest levels of activity were the same in the first session and in the second session performed 1.5 months later. Furthermore, HA seabass had lower plasma cortisol concentrations than HT fish. As HA fish had lower cortisol concentration, higher levels of activity and took more risks (the 3 characteristics of a proactive coping style), we can argue that HA seabass are proactive individuals. These results conflict with those of Laursen et al. (2011) for rainbow trout, providing another example of species specificity in behavioural responses. They also suggested that reactive trout moved to the normoxia tank due to a strong social dominance of proactive individuals in the home tank (Laursen et al. 2013) and greater sensitivity to environmental changes. We found that there were essentially no aggressive interactions between congeners and so we rejected this hypothesis. One explanation for the differences between our results and those of Laursen et al. (2011) is the use by Laursen et al. of rainbow trout from strains selected for low and high levels of post-stress cortisol release (Pottinger and Carrick, 1999), whereas our seabass were merely domesticated and therefore displayed a behavioural response similar to that of wild individuals. Indeed, some studies have highlighted the importance of studies comparing wild and selected animals (David et al., 2012), because selection may modify the behaviour of individuals (Vandeputte and Prunet, 2002; Bégout Anras and Lagardère, 2004; Millot et al., 2010; Benhaïm et al., 2012; Stryjek et al., 2012).

HA proactive fish are probably more sensitive to hypoxia, due to their higher oxygen consumption, and have an active response to avoid stressors ("fight or flight") (Cannon, 1915; Benus et al., 1991; Koolhaas et al., 1999), leading them to escape the hypoxic environment more rapidly than reactive individuals, which are characterised by a passive response ("freeze and hide") (Engel and Schmale, 1972; Koolhaas et al., 1999). Some fish re- 
612

613

614

615

616

617

618

619

620

621

622

623

624

625

626

627

628

629

630

631

632

633

634

entered sometimes in the hypoxic zone, and these fish were among the first to escape the hypoxic conditions. They were probably frightened of being alone in an enlightened open zone, probably explaining this return behaviour.

Finally, strong individual consistency between sessions was observed for all variables measured in group-based tests. These results may reflect the greater favourability of the group situation for seabass, due to the gregarious tendencies of the juveniles of this species. Such group-based tests should therefore be favoured for the characterisation of coping style in seabass.

\subsection{Cross-context consistency and individual stability}

It remains unclear why no cross-context consistency was observed in seabass, and further investigations are required to resolve this issue. However, many of the behavioural variables assessed are known to be differently expressed in proactive and reactive animals, and the link between physiological and behavioural responses has been clearly demonstrated in both individual- and group-based tests.

Cross-context consistency is not always found, as shown by Coleman and Wilson (1998) in their study of exploratory and risk-taking behaviours in pumpkinseed sunfish Lepomis gibbosus (L.): individuals are consistent for the two traits, but an individual's exploration activity is not predictive of risk-taking. As reviewed by Dingemanse et al., (2010), most of the work on personality in animals has focused on temporal or contextual individual consistency, through the use of repeatability estimates (Bell et al., 2009; Réale et al., 2007). However, repeatability provides a population estimate that does not in itself provide information 
635 about the differences between individuals in behavioural consistency over time or in 636 different situations (Réale and Dingemanse, 2010). As such, when considering individual 637 stability, it is important to distinguish between "between" and "within" (i.e. intra) individual 638 variability (see Dingemanse et al., (2010), and Stamps et al. (2012) for the definition of 639 intraindividual variability (IIV)). The high intraindividual variability observed in some fish may 640 account for the lack of consistency over time in individual-based tests, and for the results of 641 our cross-context analysis. No repeatability was observed for the individual coefficient of 642 relative plasticity (CRP). Thus, the fish with the highest levels of plasticity were not 643 necessarily the same in different tests, and individual plasticity was highly context-specific in this species with a low level of domestication. Furthermore, CRP variation was greater in 645 individual-based tests than in group-based tests, also potentially accounting for the 646 consistency of group-based test results in this species.

647

\section{CONCLUSIONS}

649

Overall, our experiments suggest that the group-based risk-taking and hypoxia exposure tests are the most promising for the screening of coping style in seabass. The results of both these tests were consistent over time (in both the short and long term), and the response to hypoxia exposure was also predictive of the cortisol response. These tests are simple to carry out and can be used to screen large numbers of fish, an essential first step towards a possible selection programme based on behavioural profile. 

funded by the Portuguese Fundação para a Ciência e Tecnologia (FCT) grant no. FRH/BPD/72952/2010. The authors would like to thank M. F. Castanheira (CCMAR) for cortisol analyses. Experiments were conducted following approval of the Animal Care

Archard, G.A., Braithwaite, V.A., 2011. Increased exposure to predators increases both exploration and activity level in Brachyrhaphis episcopi. Journal of Fish Biology 78, 593-601.

Archard, G.A., Earley, R.L., Hanninen, A.F., Braithwaite, V.A., 2012. Correlated behaviour and stress physiology in fish exposed to different levels of predation pressure. Functional Ecology 26, 637645.

Arends RJ, Mancera JM, Munoz JL, Wendelaar Bonga SE, G, F., 1999. The stress response of the gilthead sea bream (Sparus aurata L.) to air exposure and confinement. . J. Endocrinol., 163, 149157.

Ashley, P.J., 2006. Fish welfare: Current issues in aquaculture. Applied Animal Behaviour Science 104, 199-235.

variable size. Aquaculture 185, 159-173.

Barnabé, G., 1976. Contribution à la connaissance de la biologie du loup, Dicentrarchus labrax (L.) (Poisson Serranidae). Thèse de Doctorat d'état, mention Sciences, Université des Sciences et Techniques du Languedoc, Montpellier, 426p.

Barnabé, G., 1980. Exposé synoptique des données biologiques sur le loup, Dicentrarchus labrax (Linné, 1758). Synopsis FAO Pêches 126, 70 pp.

Bas Peired, C., 2002. El Mar Mediterráneo: recursos y explotación.

Bégout Anras, M.L., Lagardère, J.P., 2004. Domestication et comportement chez les poissons téléostéens. INRA Production Animale 17, 211-215.

Bell, A.M., Hankison, S.J., Laskowski, K.L., 2009. The repeatability of behaviour: a meta-analysis. Animal Behaviour 77, 771-783.

Benhaïm, D., Péan, S., Lucas, G., Blanc, N., Chatain, B., Bégout, M.-L., 2012. Early life behavioural differences in wild caught and domesticated sea bass (Dicentrarchus labrax). Applied Animal Behaviour Science 141, 79-90.

Benus, R.F., Bohus, B., Koolhaas, J.M., Oortmerssen, G.A., 1991. Heritable variation for aggression as a reflection of individual coping strategies. Experientia 47, 1008-1019.

Biro, P.A., Beckmann, C., Stamps, J.A., 2010. Small within-day increases in temperature affects boldness and alters personality in coral reef fish. Proceedings of the Royal Society B: Biological Sciences 277, 71-77.

Bolhuis, J.E., Schouten, W.G.P., Leeuw, J.A.d., Schrama, J.W., Wiegant, V.M., 2004. Individual coping characteristics, rearing conditions and behavioural flexibility in pigs. Behavioural Brain Research 152, 351-360. 
Brelin, D., Petersson, E., Dannewitz, J., Dahl, J., Winberg, S., 2008. Frequency distribution of coping strategies in four populations of brown trout (Salmo trutta). Hormones and Behavior 53, 546-556. Brown, C., Burgess, F., Braithwaite, V., 2007. Heritable and experiential effects on boldness in a tropical poeciliid. Behavioral Ecology and Sociobiology 62, 237-243.

Brown, C., Braithwaite, V.A., 2004. Size matters: a test of boldness in eight populations of the poeciliid Brachyraphis episcopi. Animal Behaviour 68, 1325-1329.

Brown, C., Jones, F., \& Braithwaite, V. , 2005. In situ examination of boldness-shyness traits in the tropical poeciliid, Brachyraphis epidcopi. Animal Behaviour 70, 1003-1009.

Budaev, S.V., Zworykin, D.D., Mochek, A.D., 1999a. Consistency of individual differences in behaviour of the lion-headed cichlid, Steatocranus casuarius. Behavioural Processes 48, 49-55.

Cannon, W.B., 1915. Bodily changes in pain, hunger, fear and rage. New York: Appleton.

Careau, V., Thomas, D., Humphries, M.M., Réale, D., 2008. Energy metabolism and animal personality. Oikos 117, 641-653.

Castanheira, M.F., Herrera, M., Costas, B., Conceicao, L.E.C., Martins, C.I.M., 2013b. Can We Predict Personality in Fish? Searching for Consistency over Time and across Contexts. PLoS ONE 8, e62037.

Castanheira, M.F., Herrera, M., Costas, B., Conceição, L.E.C., Martins, C.I.M., 2013a. Linking cortisol responsiveness and aggressive behaviour in gilthead seabream Sparus aurata: Indication of divergent coping styles. Applied Animal Behaviour Science 143, 75-81.

Chapman, B.B., Morrell, L.J., Benton, T.G., Krause, J., 2008. Early interactions with adults mediate the development of predator defenses in guppies. Behavioral Ecology 19, 87-93.

Chapman, B.B., Morrell, L.J., Krause, J., 2010. Unpredictability in food supply during early life influences boldness in fish. Behavioral Ecology 21, 501-506.

Coleman, K., Wilson, D.S., 1998. Shyness and boldness in pumpkinseed sunfish: individual differences are context-specific. Animal Behaviour 56, 927-936.

David, M., Auclair, Y., Cézilly, F., 2012. Assessing Short- and Long-Term Repeatability and Stability of Personality in Captive Zebra Finches Using Longitudinal Data. Ethology 118, 932-942.

de Boer, S.F., de Beun, R., Slangen, J.L., van der Gugten, J., 1990. Dynamics of plasma catecholamine and corticosterone concentrations during reinforced and extinguished operant behavior in rats. Physiology \& Behavior 47, 691-698.

Dingemanse, N.J., Barber, I., Wright, J., Brommer, J.E., 2012. Quantitative genetics of behavioural reaction norms: genetic correlations between personality and behavioural plasticity vary across stickleback populations. Journal of Evolutionary Biology 25, 485-496.

Dingemanse, N.J., Both, C., Drent, P.J., van Oers, K., van Noordwijk, A.J., 2002. Repeatability and heritability of exploratory behaviour in great tits from the wild. Animal Behaviour 64, 929-938.

Dingemanse, N.J., Kazem, A.J.N., Réale, D., Wright, J., 2010. Behavioural reaction norms: animal personality meets individual plasticity. Trends in Ecology \&amp; Evolution 25, 81-89.

Dunbrack, R.L., Clarke, L., Bassler, C., 1996. Population level differences in aggressiveness and their relationship to food density in a stream salmonid (Salvelinus fontinalis). Journal of Fish Biology 48, 615-622.

Engel, G., Schmale, A., 1972. Conservation withdrawal: a primary regulatory process for organic homeostasis. Physiology, emotions and psychosomatic illness, Elsevier57-95.

Fanouraki, E., Mylonas, C.C., Papandroulakis, N., Pavlidis, M., 2011. Species specificity in the magnitude and duration of the acute stress response in Mediterranean marine fish in culture. General and Comparative Endocrinology 173, 313-322.

Ferrari, S., Chatain, B., Cousin, X., Leguay, D., Vergnet, A., Vidal, M.-O.,Vandeputte, M., Bégout, M.L., 2014. Early individual electronic iden-tification of sea bass using RFID microtags: A first example of earlyphenotyping of sex-related growth. Aquaculture 426-427, 165-171.

Ferrari, S., Benhaïm, D., Colchen, T., Chatain, B., Bégout, M.L., 2014b. First links between selffeeding behaviour and personality traits in European seabass, Dicentrarchus labrax. Applied Animal Behaviour Science 161 (2014) 131-141.

Fevolden, S.E., Nordmo, R., Refstie, T., Røed, K.H., 1993. Disease resistance in Atlantic salmon (Salmo salar) selected for high or low responses to stress. Aquaculture 109, 215-224. 
Gregory, T.R., Wood, C.M., 1999. The Effects of Chronic Plasma Cortisol Elevation on the Feeding

Behaviour, Growth, Competitive Ability, and Swimming Performance of Juvenile Rainbow Trout. Physiological and Biochemical Zoology 72, 286-295.

Herrera, M., Castanheira, M.F., Conceição, L.E.C., Martins, C.I., 2014. Linking risk taking and the behavioral and metabolic responses to confinement stress in gilthead seabream Sparus aurata. Applied Animal Behaviour Science 155, 101-108.

Huntingford, F.A., Adams, C., 2005. Behavioural syndromes in farmed fish: implications for production and welfare. Behaviour 142, 1207-1221.

Huntingford, F.A., Andrew, G., Mackenzie, S., Morera, D., Coyle, S.M., Pilarczyk, M., Kadri, S., 2010. Coping strategies in a strongly schooling fish, the common carp Cyprinus carpio. Journal of Fish Biology 76, 1576-1591.

Killen, S.S., Marras, S., Ryan, M.R., Domenici, P., McKenzie, D.J., 2011. A relationship between metabolic rate and risk-taking behaviour is revealed during hypoxia in juvenile European sea bass. Functional Ecology 26, 134-143.

Koolhaas, J.M., 2008. Coping style and immunity in animals: Making sense of individual variation. Brain, Behavior, and Immunity 22, 662-667.

Koolhaas, J.M., Korte, S.M., De Boer, S.F., Van Der Vegt, B.J., Van Reenen, C.G., Hopster, H., De Jong, I.C., Ruis, M.A.W., Blokhuis, H.J., 1999. Coping styles in animals: current in behavior and stress-physiology. Neuroscience and Biobehavioral Reviews 23, 925-935.

Laursen, D.C., L. Olsén, H., Ruiz-Gomez, M.d.L., Winberg, S., Höglund, E., 2011. Behavioural responses to hypoxia provide a non-invasive method for distinguishing between stress coping styles in fish. Applied Animal Behaviour Science 132, 211-216.

Laursen, D. C., Andersson, M. Å., Silva, P. I. M., Petersson, E., \& Höglund, E. (2013). Utilising spatial distribution in two-tank systems to investigate the level of aversiveness to crowding in farmed rainbow trout Oncorhynchus mykiss. Applied Animal Behaviour Science, 144(3), 163-170.

LeBlanc S, Höglund E, Gilmour KM, S, C., 2012. Hormonal modulation of the heat shock response: insights from fish with divergent cortisol stress responses.

MacKenzie, S., Ribas, L., Pilarczyk, M., Capdevila, D.M., Kadri, S., Huntingford, F.A., 2009. Screening for Coping Style Increases the Power of Gene Expression Studies. PLoS ONE 4, e5314.

Martins, C.I.M., Castanheira, M.F., Engrola, S., Costas, B., Conceicao, L.E.C., 2011a. Individual differences in metabolism predict coping styles in fish. Applied Animal Behaviour Science 130, 135143.

Martins, C.I.M., Conceição, L.E.C., Schrama, J.W., 2011b. Consistency of individual variation in feeding behaviour and its relationship with performance traits in Nile tilapia Oreochromis niloticus. Applied Animal Behaviour Science 133, 109-116.

Martins, C.I.M., Schrama, J.W., Verreth, J.A.J., 2005. The consistency of individual differences in growth, feed efficiency and feeding behaviour African catfish Clarias gariepinus (Burchell 1822) housed individually. Aquaculture Research 36, 1509-1516.

Martins, C.I.M., Silva, P.I.M., Conceição, L.E.C., Costas, B., Höglund, E., Overli, O., Schrama, J.W., 2011c. Linking fearfulness and coping styles in fish. PLoS ONE 6, e28084.

Millot, S., Bégout, M.L., Chatain, B., 2009. Risk-taking behaviour variation over time in sea bass Dicentrarchus labrax: effects of day-night alternation, fish phenotypic characteristics and selection for growth. Journal of Fish Biology 75, 1733-1749.

Millot, S., Péan, S., Leguay, D., Vergnet, A., Chatain, B., Bégout, M.L., 2010. Evaluation of behavioral changes induced by a first step of domestication or selection for growth in the European sea bass (Dicentrarchus labrax): A self-feeding approach under repeated acute stress. Aquaculture 306, 211-217.

Nakagawa, S., \& Schielzeth, H. (2010). Repeatability for Gaussian and non-Gaussian data: a practical guide for biologists. Biological Reviews, 85(4), 935-956.

Nespolo, R.F., Franco, M., 2007. Whole-animal metabolic rate is a repeatable trait: a meta-analysis. Journal of Experimental Biology 210, 3877-3878. 
Ninkovic, J., Bally-Cuif, L., 2006. The zebrafish as a model system for assessing the reinforcing properties of drugs of abuse. Methods 39, 262-274.

Nunnally, J.C., 1967. Pshycometric Theory. McGraw-Hill, New York.

Oikawa, S., Itazawa, Y., 1985. Gill and Body Surface Areas of the Carp in relation to Body Mass, With Special Reference To The Metabolism-Size Relationship. Journal of Experimental Biology 117, 1-14.

$\emptyset$ verli, Ø., Korzan, W.J., Höglund, E., Winberg, S., Bollig, H., Watt, M., Forster, G.L., Barton, B.A., $\varnothing v e r l i$, E., Renner, K.J., Summers, C.H., 2004. Stress coping style predicts aggression and social dominance in rainbow trout. Hormones and Behavior 45, 235-241.

$\varnothing v e r l i, \varnothing$., Sørensen, C., Nilsson, G.E., 2006. Behavioral indicators of stress-coping style in rainbow trout: Do males and females react differently to novelty? Physiology \& behavior 87, 506-512.

$\emptyset$ verli, $\emptyset$., Sorensen, C., Pulman, K.G.T., Pottinger, T.G., Korzan, W., Summers, C.H., Nilsson, G.E., 2007. Evolutionary background for stress-coping styles: Relationships between physiological, behavioral, and cognitive traits in non-mammalian vertebrates. Neuroscience \&amp; Biobehavioral Reviews 31, 396-412.

$\varnothing v e r l i, \varnothing .$, Winberg, S., Pottinger, T.G., 2005. Behavioral and Neuroendocrine Correlates of Selection for Stress Responsiveness in Rainbow Trout-a Review. Integrative and Comparative Biology 45, 463-474.

Pottinger, T.G., Carrick, T.R., 1999. Modification of plasma cortisol response to stress in rainbow trout by selective breeding. General and Comparative Endocrinology 116, 122-132.

Réale, D., Dingemanse, N.J., 2010. Personality and individual social specialisation. Social Behaviour: Genes, Ecology and Evolution, 527-557.

Réale, D., Reader, S.M., Sol, D., McDougall, P.T., Dingemanse, N.J., 2007a. Integrating animal temperament within ecology and evolution. Biological Reviews of the Cambridge Philosophical Society 82, 291-318.

Réale, D., Reader, S.M., Sol, D., McDougall, P.T., Dingemanse, N.J., 2007b. Integrating animal temperament within ecology and evolution. Biological Reviews 82, 291-318.

Rexroad, C., Vallejo, R., Liu, S., Palti, Y., Weber, G., 2012. QTL affecting stress response to crowding in a rainbow trout broodstock population. BMC Genetics 13, 97.

Reyes-Tomassini, J.J., 2009. Behavioral and Neuroendocrine Correlates of Sex Change in the Gilthead Seabream Sparus aurata. Biotechnology Institute University of Maryland, 229.

Rotllant, J., Ruane, N.M., Caballero, M.J., Montero, D., Tort, L., 2003. Response to confinement in sea bass (Dicentrarchus labrax) is characterised by an increased biosynthetic capacity of interrenal tissue with no effect on ACTH sensitivity. Comparative Biochemistry and Physiology Part A: Molecular \& Integrative Physiology 136, 613-620.

Ruiz-Gomez, M.d.L., Huntingford, F.A., Øverli, Ø., Thörnqvist, P.-O., Höglund, E., 2011. Response to environmental change in rainbow trout selected for divergent stress coping styles. Physiology \& behavior 102, 317-322.

Ruiz-Gomez, M.d.L., Kittilsen, S., Höglund, E., Huntingford, F.A., Sørensen, C., Pottinger, T.G., Bakken, M., Winberg, S., Korzan, W.J., Øverli, Ø., 2008. Behavioral plasticity in rainbow trout (Oncorhynchus mykiss) with divergent coping styles: When doves become hawks. Hormones and Behavior 54, 534-538.

Scherrer B (1984) Biostatistique. Chicoutimi, Canada: Gaëtan morin.

Silva, P.I.M., Martins, C.I.M., Engrola, S., Marino, G., Øverli, Ø., Conceição, L.E.C., 2010. Individual differences in cortisol levels and behaviour of Senegalese sole (Solea senegalensis) juveniles: Evidence for coping styles. Applied Animal Behaviour Science 124, 75-81.

Stamps, J.A., Briffa, M., Biro, P.A., 2012. Unpredictable animals: individual differences in intraindividual variability (IIV). Animal Behaviour 83, 1325-1334.

Stryjek, R., Modlińska, K., Pisula, W., 2012. Species Specific Behavioural Patterns (Digging and Swimming) and Reaction to Novel Objects in Wild Type, Wistar, Sprague-Dawley and Brown Norway Rats. PLoS ONE 7, e40642.

Tveteras, R., Nystoyl, R., 2011. Fish production Estimates \& trends 2011-2012 Santiago, Chile. 
van Oers, K., Drent, P.J., de Goede, P., van Noordwijk, A.J., 2004. Realized heritability and repeatability of risk-taking behaviour in relation to avian personalities. Proceedings of the Royal Society of London. Series B: Biological Sciences 271, 65-73. Vandeputte, M., Prunet, P., 2002. Génétique et adaptation chez les poissons : domestication, résistance au stress et adaptation aux conditions de milieu. INRA Productions Animales 15, 365371.

Veenema, A.H., Meijer, O.C., de Kloet, E.R., Koolhaas, J.M., 2003. Genetic selection for coping style predicts stressor susceptibility. Journal of Neuroendocrinology 15, 256-267. Wilson, A.D.M., Godin, J.-G.J., 2009. Boldness and behavioral syndromes in the bluegill sunfish, Lepomis macrochirus, pp. 231-237. Wilson, A.D.M., Stevens, E.D., 2005. Consistency in Context-specific Measures of Shyness and Boldness in Rainbow Trout, Oncorhynchus mykiss. Ethology 111, 849-862. Wilson, A.M., Whattam, E., Bennett, R., Visanuvimol, L., Lauzon, C., Bertram, S., 2010. Behavioral correlations across activity, mating, exploration, aggression, and antipredator contexts in the European house cricket, Acheta domesticus. Behavioral Ecology and Sociobiology 64, 703-715. Wolf, M., Van Doorn, S., Leimar, O., Weissing, F.J., 2007. Life-history trade-offs favour the evolution of animal personalities. Nature, 581-585.

Wright, D., Nakamichi, R., Krause, J., Butlin, R., 2006. QTL Analysis of Behavioral and Morphological 284. 


\section{List of figures:}

875 Figure 1: Diagram and dimensions of the T maze used for the exploration test (tests 3-1 and $876 \quad 3-2)$.

877 Figure 2: Relative occurrence of each feeding score (according to the scoring table from $\varnothing$ verli et al., 2007). A: session 1 (test 1-1); B: session 2 (test 1-2); C: session 3 (test 1-3).

879

880

881

882

883

884

885

886

887

888

889

890

891

892

Figure 3: Number of escape attempts at each session of the net restraint test (tests 4-1; 4-2 and 4-3; mean \pm SD). Different letters indicate significant differences between sessions $(p<0.05)$

Figures 4: Correlations between the number of returns to the safe zone during the risktaking test: $A$, in sessions 1 (test 5-1) and 2 (test 5-2) and B, in sessions 2 (test 5-2) and 3 (test 5-3).

Figures 5: Correlations between risk-taking behaviour (escape order) and activity level (number of returns to the safe zone): A during session 1 (test $5-1$ ) and B during session 2 (test 5-2).

Figure 6: Individual consistency in risk-taking behaviour: A, between sessions 1 (test 5-1) and 2 (test $5-2$ ) and B, between sessions 2 (test 5-2) and 3 (test 5-3).

Figure 7: Correlations between hypoxia tolerance in sessions 1 (test 6-1) and 2 (test 6-2).

Figures 8: Link between behavioural and physiological responses; A, relationship between plasma cortisol concentration 30 minutes after the net restraint test in session 1 (test 4-1) 
893 and the number of escape attempts during the net restraint test in session 1. B, relationship

894 between individual oxygen level (\%) at first passage into the normoxia tank during the 895 hypoxia test in session 1 (test 6-1) and cortisol concentration at the end of this test.

896 
897 Table 1: List of the behavioural tests applied to seabass, with the corresponding age in days

898 post hatching (dph) and fish body weight (mean \pm SD) and the time interval (in days)

899 between tests. The number of fish tested differs between tests because some fish were

900 removed from the analysis due to technical problems or abnormal behaviour.

\begin{tabular}{|c|c|c|c|c|c|}
\hline Individual based test & $\begin{array}{l}\text { Fish age } \\
\text { (dph) }\end{array}$ & $\begin{array}{c}\text { Time interval between } \\
\text { sessions (days) }\end{array}$ & $\begin{array}{c}\text { Fish BW } \\
(\mathrm{g}, \text { mean } \pm \mathrm{sd})\end{array}$ & $\begin{array}{c}\text { Test } \\
\text { number }\end{array}$ & $\begin{array}{c}\mathbf{N} \text { (number } \\
\text { of fish } \\
\text { tested) }\end{array}$ \\
\hline Feeding Recovery \#1 & 129 & & $2.55 \pm 0.55$ & $1-1$ & 30 \\
\hline Feeding Recovery \#2 & 283 & 154 & $17.67 \pm 2.95$ & $1-2$ & 29 \\
\hline Feeding Recovery \#3 & 548 & 265 & $179.54 \pm 35.20$ & $1-3$ & 21 \\
\hline Aggression test & 137 & & $2.68 \pm 0.45$ & $2-1$ & 24 \\
\hline Exploration test T-M aze \#1 & 150 & & $5.31 \pm 1.00$ & $3-1$ & 25 \\
\hline Exploration test T-Maze \#2 & 311 & 161 & $27.53 \pm 4.69$ & $3-2$ & 17 \\
\hline Restraint test \#1 & 557 & & $179.54 \pm 35.20$ & $4-1$ & 22 \\
\hline Restraint test \#2 & 739 & 182 & $552.01 \pm 112.36$ & $4-2$ & 22 \\
\hline Restraint test \#3 & 758 & 19 & $639.35 \pm 134.43$ & $4-3$ & 17 \\
\hline \multicolumn{6}{|l|}{ Group based test } \\
\hline Risk taking test \#1 & 187 & & - & $5-1$ & 30 \\
\hline Risk taking test \#2 & 202 & 15 & $10.13 \pm 2.09$ & $5-2$ & 30 \\
\hline Risk taking test \#3 & 216 & 14 & $10.92 \pm 2.07$ & $5-3$ & 30 \\
\hline Hypoxia test \#1 & 457 & & $117.01 \pm 21.50$ & $6-1$ & 24 \\
\hline Hypoxia test \#2 & 502 & 45 & - & $6-2$ & 24 \\
\hline \multicolumn{6}{|l|}{ Physiological measures } \\
\hline Blood sampling \#1 & 290 & - & $17.67 \pm 2.95$ & after $1-2$ & 16 \\
\hline Blood sampling \#2 & 457 & - & $117.01 \pm 21.50$ & after 6-1 & 15 \\
\hline Blood sampling \#3 & 557 & - & $179.54 \pm 35.20$ & after $4-1$ & 22 \\
\hline
\end{tabular}


Table 2: Means $( \pm S D)$ of the variables of interest measured during sessions 1, 2 and 3 of the individual- and group-based screening tests; inter-

904 individual variation is represented by the coefficient of variation ((CV =standard deviation / mean * 100), \%).

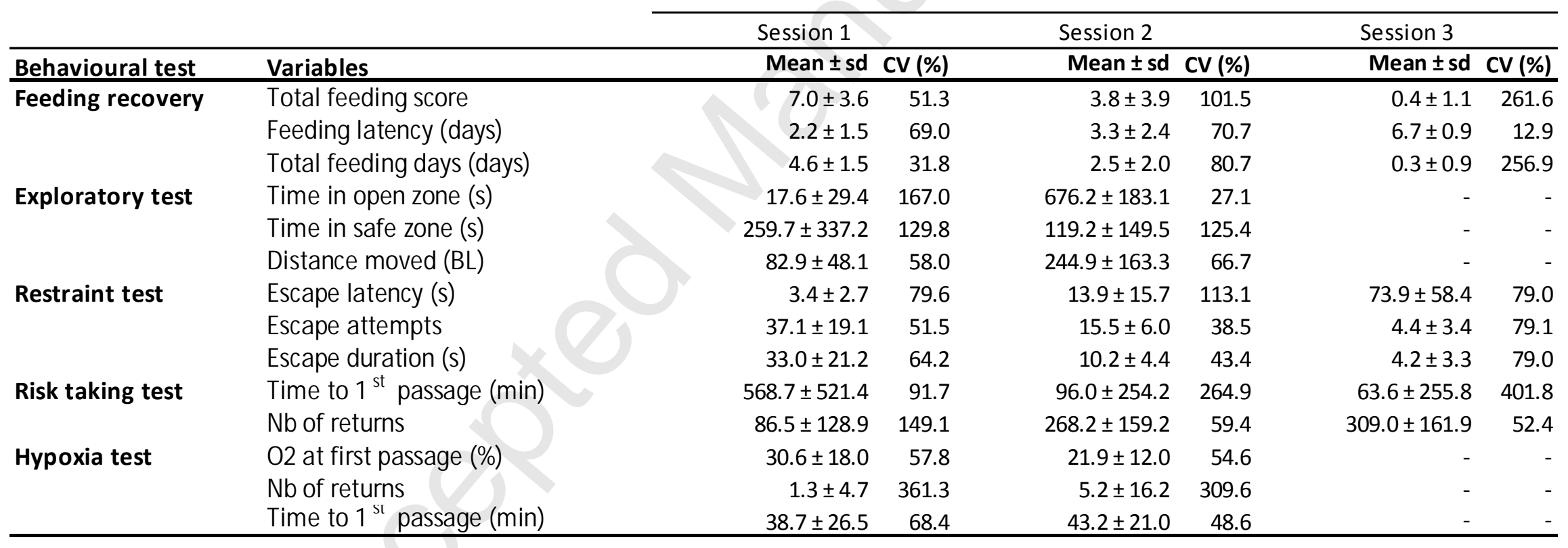


Table 3: Eigen values, contribution of variables and eigen vector for the 1st axis (PC1) obtained during the PCA analyses in the different

910 behavioural tests.

\begin{tabular}{|c|c|c|c|c|c|c|c|}
\hline \multirow[b]{2}{*}{ Behavioural test } & \multirow[b]{2}{*}{ Variables } & \multirow{2}{*}{\multicolumn{2}{|c|}{ Session 1}} & \multirow{2}{*}{\multicolumn{2}{|c|}{ Session 2}} & \multirow{2}{*}{\multicolumn{2}{|c|}{ Session 3}} \\
\hline & & & & & & & \\
\hline \multirow{5}{*}{ Feeding recovery } & & PC1_eigen (\%) & 91.20 & PC1_eigen (\%) & 84.80 & PC1_eigen (\%) & 97.20 \\
\hline & & Contribution of variables & Eigen_vector & Contribution of variables & Eigen_vector & Contribution of variables & Eigen_vector \\
\hline & Total feeding score & 0.31 & 0.56 & 0.33 & 0.57 & 0.32 & 0.57 \\
\hline & Feeding latency & 0.33 & -0.58 & 0.30 & -0.55 & 0.34 & -0.58 \\
\hline & Total feeding day & 0.35 & 0.60 & 0.37 & 0.61 & 0.34 & 0.58 \\
\hline \multirow{6}{*}{ Exploration } & & PC1_eigen (\%) & $38.10 \%$ & PC1_eigen (\%) & $46.10 \%$ & & \\
\hline & & Contribution of variables & Eigen_vector & Contribution of variables & Eigen_vector & & \\
\hline & Time to entry in open zone & 0.19 & -0.43 & 0.22 & -0.47 & & \\
\hline & Time in open zone & 0.11 & 0.33 & 0.49 & 0.70 & & \\
\hline & Time in safe zone & 0.41 & 0.64 & 0.18 & -0.42 & & \\
\hline & Distance moved & 0.29 & 0.54 & 0.12 & 0.34 & & \\
\hline \multirow{5}{*}{ Net restraint } & & PC1_eigen (\%) & 60.10 & PC1_eigen (\%) & 63.10 & PC1_eigen (\%) & 63.80 \\
\hline & & Contribution of variables & Eigen_vector & Contribution of variables & Eigen_vector & Contribution of variables & Eigen_vector \\
\hline & $\mathrm{Nb}$ attemps to escape & 0.45 & 0.67 & 0.35 & 0.59 & 0.49 & 0.70 \\
\hline & Latency to first ecape & 0.12 & -0.34 & 0.30 & -0.55 & 0.04 & -0.20 \\
\hline & Total escape duration & 0.43 & 0.66 & 0.35 & 0.59 & 0.47 & 0.69 \\
\hline \multirow{5}{*}{ Risk taking } & & PC1_eigen (\%) & 72.80 & PC1_eigen (\%) & 66.10 & PC1_eigen (\%) & 52.40 \\
\hline & & Contribution of variables & Eigen_vector & Contribution of variables & Eigen_vector & Contribution of variables & Eigen_vector \\
\hline & $\mathrm{Nb}$ return & 0.18 & 0.43 & 0.37 & 0.61 & 0.30 & 0.55 \\
\hline & Escape order & 0.40 & -0.64 & 0.39 & -0.62 & 0.27 & -0.52 \\
\hline & Emergence time & 0.41 & -0.64 & 0.24 & -0.49 & 0.43 & -0.65 \\
\hline \multirow{5}{*}{ Hypoxia } & & PC1_eigen (\%) & 75.40 & PC1_eigen (\%) & 81.90 & & \\
\hline & & Contribution of variables & Eigen_vector & Contribution of variables & Eigen_vector & & \\
\hline & $\mathrm{Nb}$ return & 0.21 & 0.46 & 0.24 & 0.49 & & \\
\hline & Escape order & 0.41 & -0.64 & 0.38 & -0.61 & & \\
\hline & Latency before first passage & 0.37 & -0.61 & 0.38 & -0.62 & & \\
\hline
\end{tabular}


913 Table 4: Analyses of cross-context consistency by PCA based on correlations of $\mathrm{PC} 1_{\mathrm{s}}$ (mean

914 of sessions 1 and 2 ) between behavioural tests ( $r_{s}$ is the value of the Spearman correlation,

$915 r_{s(\mathrm{~N}=24)}>0.476$ would be significant for $\alpha=0.05$ corrected using Bonferroni method using $n=5$

916 tests).

\begin{tabular}{|c|c|c|c|c|c|}
\hline $\begin{array}{l}\text { Cross-context } \\
\text { consistency }\end{array}$ & $\begin{array}{l}\text { Feeding } \\
\text { recovery }\end{array}$ & Exploration & Restraint & Risk-taking & $\begin{array}{c}\text { Hypoxia } \\
\text { test }\end{array}$ \\
\hline $\begin{array}{l}\text { Feeding } \\
\text { recovery }\end{array}$ & - & $r_{s}=0.054$ & $r_{s}=-0.08$ & $r_{s}=0.13$ & $r_{S}=-0.06$ \\
\hline Exploration & - & - & $r_{s}=0.31$ & $r_{s}=-0.26$ & $r_{s}=-0.29$ \\
\hline Restraint & - & & - & $r_{s}=0.07$ & $r_{S}=-0.22$ \\
\hline Risk-taking & - & & - & - & $r_{s}=0.18$ \\
\hline Hypoxia & - & - & - & - & - \\
\hline
\end{tabular}

917 
918 Table 5: Individual coefficients of relative plasticity $\left(\mathrm{CRP}_{\mathrm{i}}\right)$ for each behavioural test, 919 calculated as described by Réale and Dingemanse (2010). $F=$ female and $M=$ male, NA 920 indicates fish removed from T-maze experiment analyses or fish not tested in all contexts.

\begin{tabular}{rcccccc}
\hline ID & Sex & $\begin{array}{c}\text { Feeding } \\
\text { recovery }\end{array}$ & Exploration & $\begin{array}{c}\text { Net } \\
\text { restraint }\end{array}$ & $\begin{array}{c}\text { Risk- } \\
\text { taking }\end{array}$ & Hypoxia \\
\hline 1 & $\mathrm{~F}$ & 0.02 & 0.06 & 1.31 & 0.09 & 0.00 \\
2 & $\mathrm{M}$ & 0.77 & $\mathrm{NA}$ & 0.41 & 0.53 & 0.00 \\
3 & $\mathrm{~F}$ & 0.03 & 3.40 & 0.19 & 0.24 & 0.00 \\
4 & $\mathrm{~F}$ & 0.62 & $\mathrm{NA}$ & 0.72 & 1.23 & 0.35 \\
5 & $\mathrm{~F}$ & 0.81 & $\mathrm{NA}$ & 0.05 & 0.70 & 1.18 \\
6 & $\mathrm{~F}$ & 0.00 & $\mathrm{NA}$ & 0.70 & 0.56 & 0.22 \\
7 & $\mathrm{~F}$ & 0.69 & 0.02 & 0.96 & 1.24 & 1.20 \\
8 & $\mathrm{M}$ & 0.29 & $\mathrm{NA}$ & 0.07 & 0.63 & 0.03 \\
9 & $\mathrm{~F}$ & 2.53 & $\mathrm{NA}$ & 0.61 & 0.30 & 0.02 \\
10 & $\mathrm{M}$ & 0.49 & 0.06 & 1.46 & 0.29 & 0.06 \\
11 & $\mathrm{M}$ & 0.11 & 0.58 & 1.41 & 0.45 & 0.00 \\
12 & $\mathrm{~F}$ & 0.08 & $\mathrm{NA}$ & 0.35 & 1.17 & 0.00 \\
13 & $\mathrm{~F}$ & 0.99 & 0.92 & 0.16 & 0.05 & 0.27 \\
14 & $\mathrm{~F}$ & 1.68 & 0.01 & 0.02 & 0.08 & 0.19 \\
15 & $\mathrm{~F}$ & 0.23 & 0.14 & 1.38 & 0.11 & 0.15 \\
16 & $\mathrm{M}$ & 2.45 & 0.18 & 1.81 & 0.68 & 0.00 \\
17 & $\mathrm{M}$ & 0.65 & 0.02 & 0.68 & 1.64 & 0.00 \\
18 & $\mathrm{~F}$ & 0.79 & $\mathrm{NA}$ & 1.92 & 0.46 & 0.00 \\
19 & $\mathrm{M}$ & 3.06 & $\mathrm{NA}$ & 2.21 & 0.15 & 1.33 \\
20 & $\mathrm{~F}$ & 0.51 & 0.01 & 0.34 & 0.26 & 0.29 \\
21 & $\mathrm{M}$ & 1.28 & 0.00 & 0.00 & 0.81 & 0.00 \\
22 & $\mathrm{M}$ & 0.20 & 0.01 & 0.89 & 0.79 & 0.02 \\
22 & $\mathrm{M}$ & 0.20 & 0.01 & 0.89 & 0.79 & 0.02 \\
\hline $\mathrm{Mean}$ & & 0.87 & 0.42 & 0.80 & 0.57 & 0.24 \\
\hline $\mathrm{SD}$ & & 0.83 & 0.94 & 0.67 & 0.44 & 0.42 \\
\hline & & & & & & \\
\hline
\end{tabular}

921

922 
$923 \quad$ Figure 1

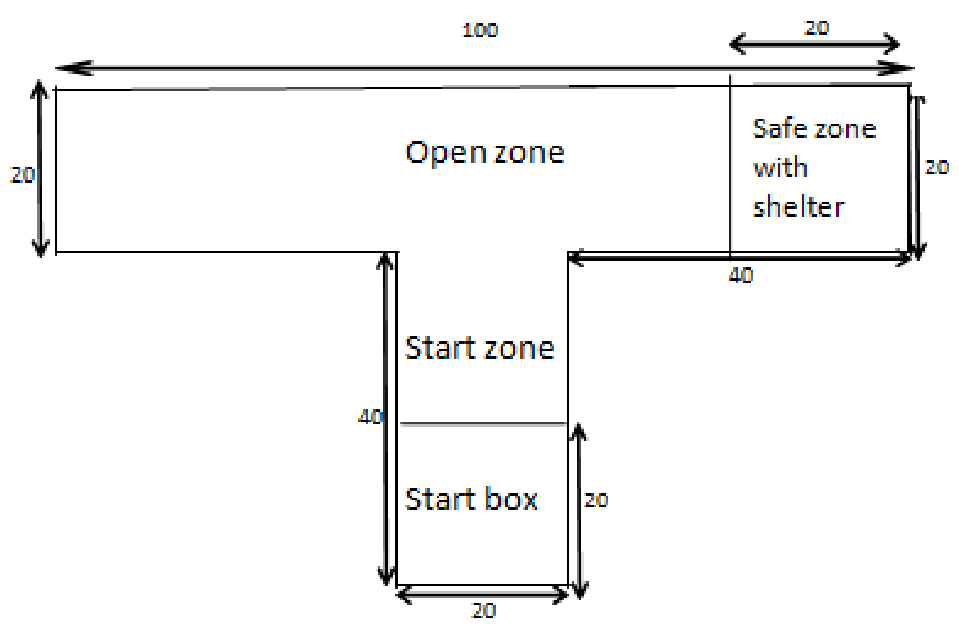

924

925 
$926 \quad$ Figure 2

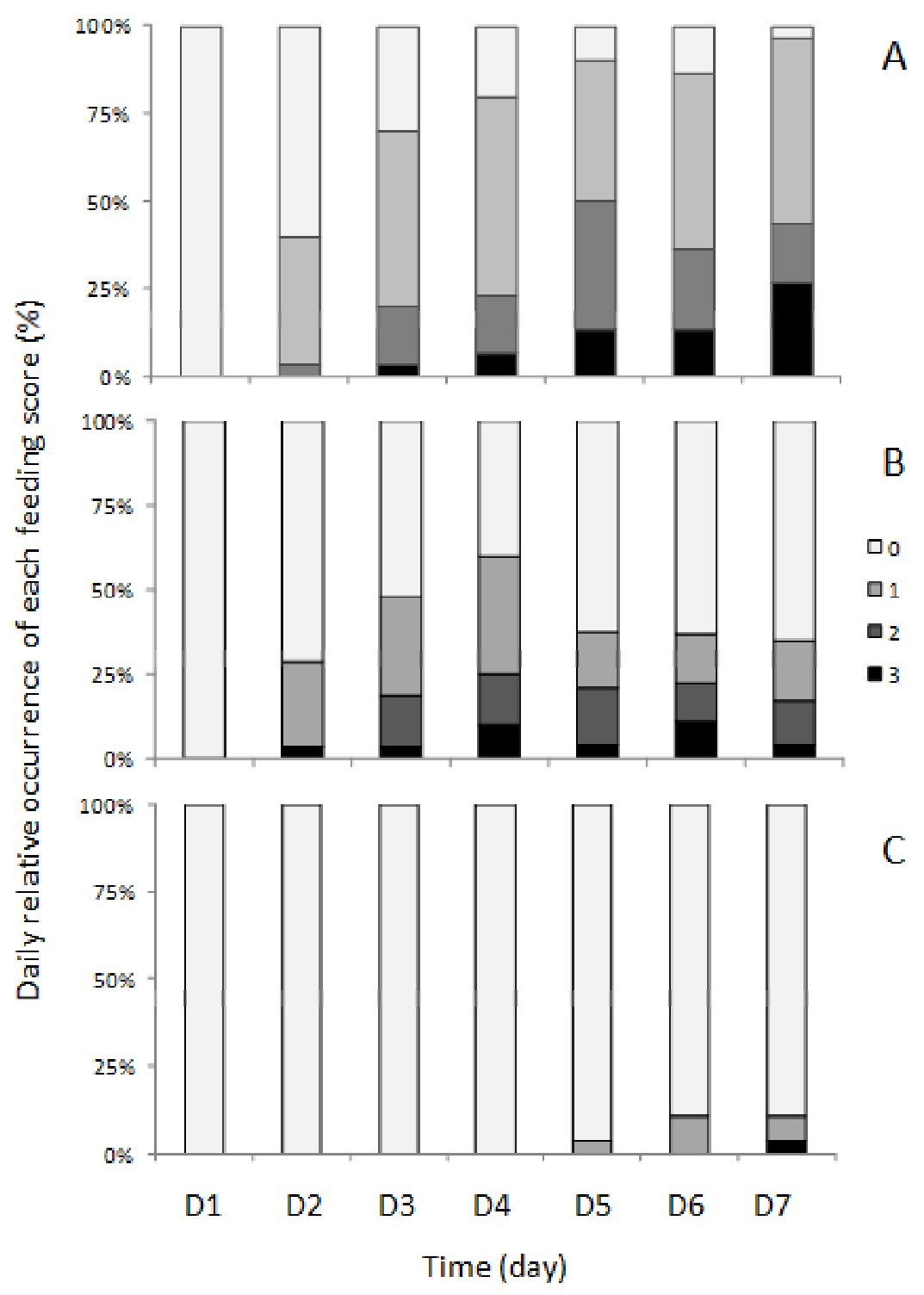




\section{$929 \quad$ Figure 3}

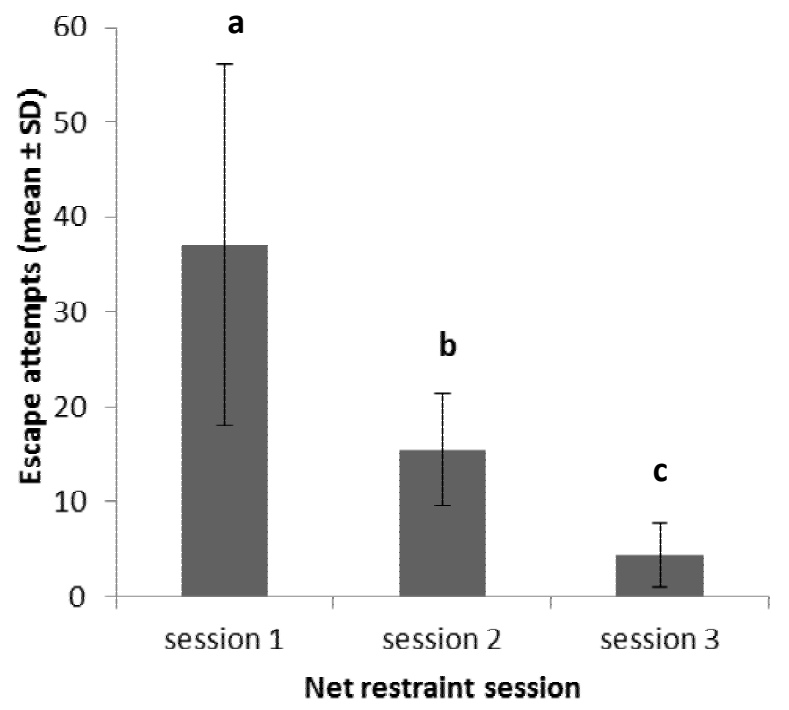

930

931 
931

932

$933 \quad$ Figure 4

934
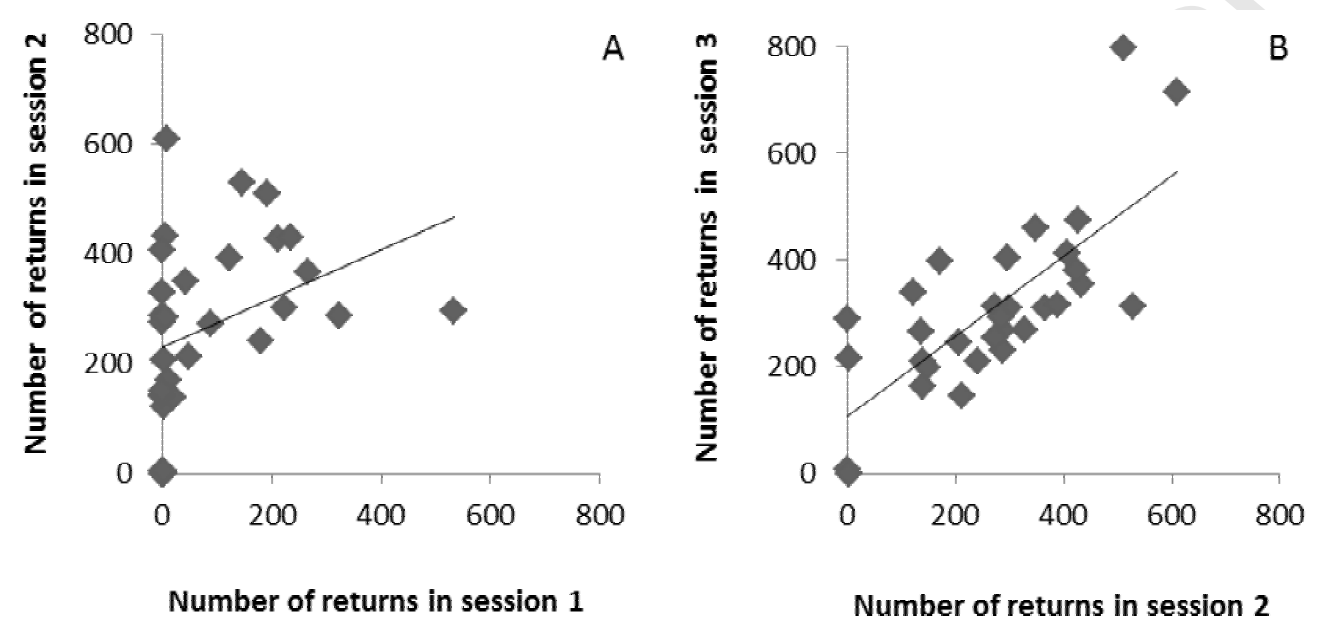

935

936 
936

$937 \quad$ Figure 5
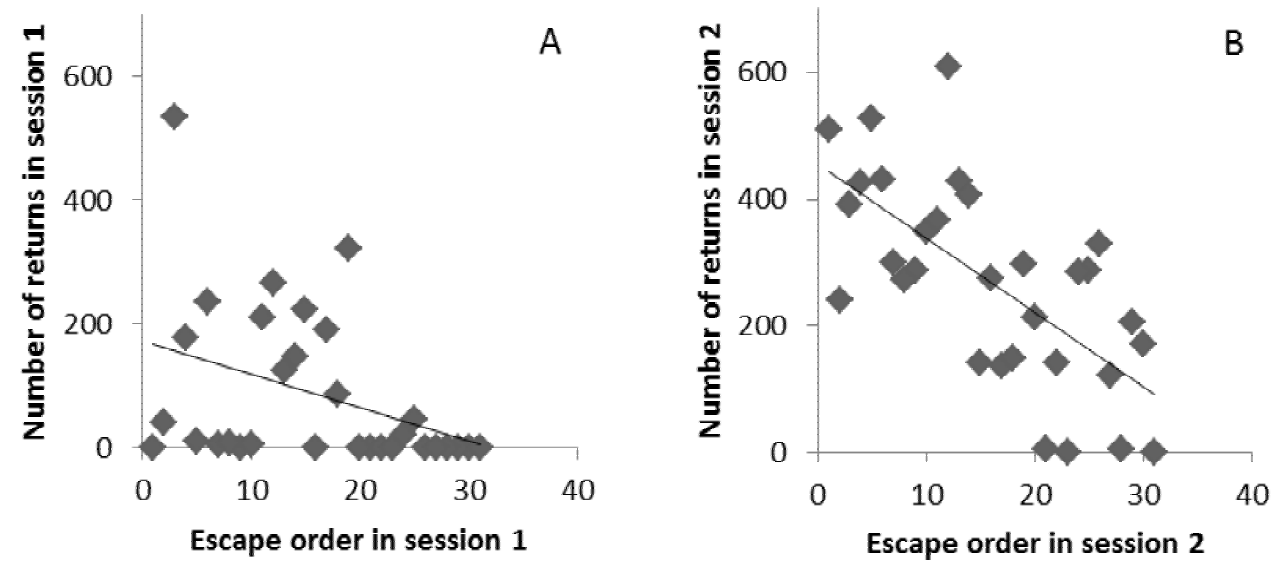

939 
939

$940 \quad$ Figure 6

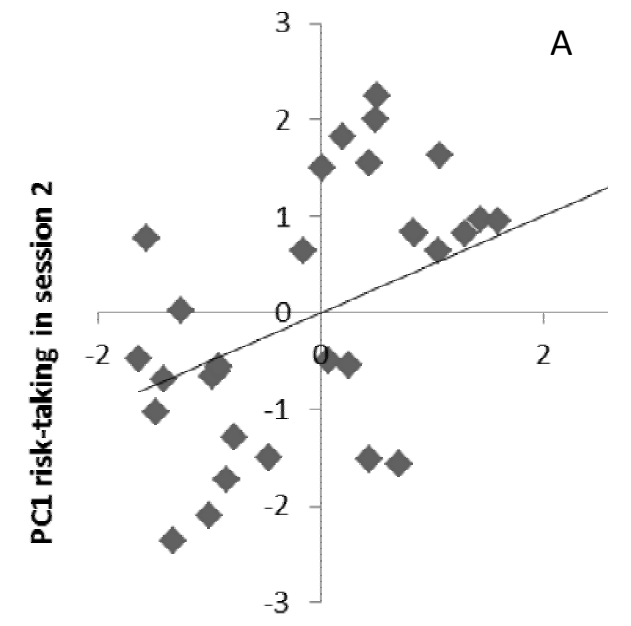

PC1 risk-taking in session 1

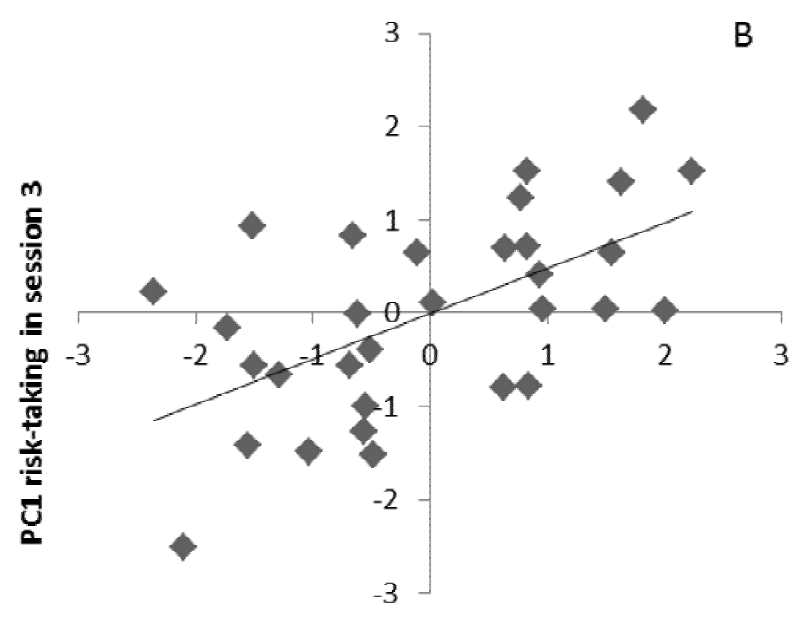

PC1 risk-taking in session 2

942 
942

$943 \quad$ Figure 7

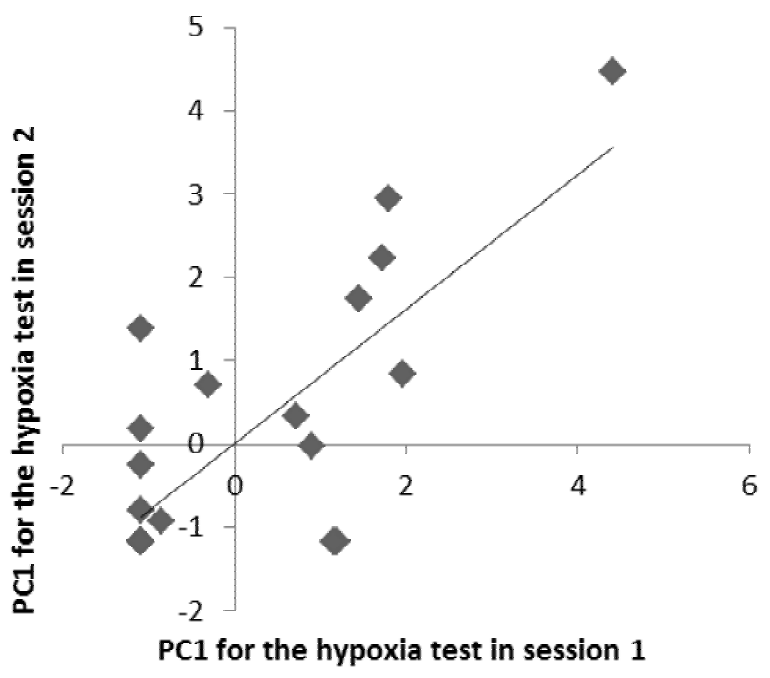

944

945 
945

$946 \quad$ Figure

947

8



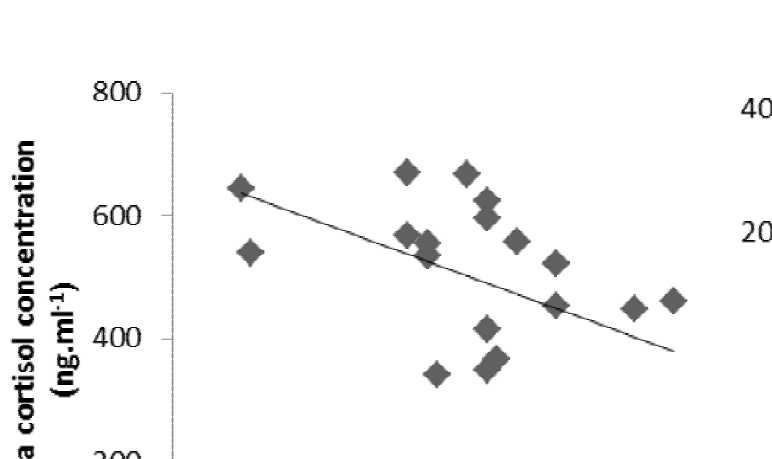

800

B
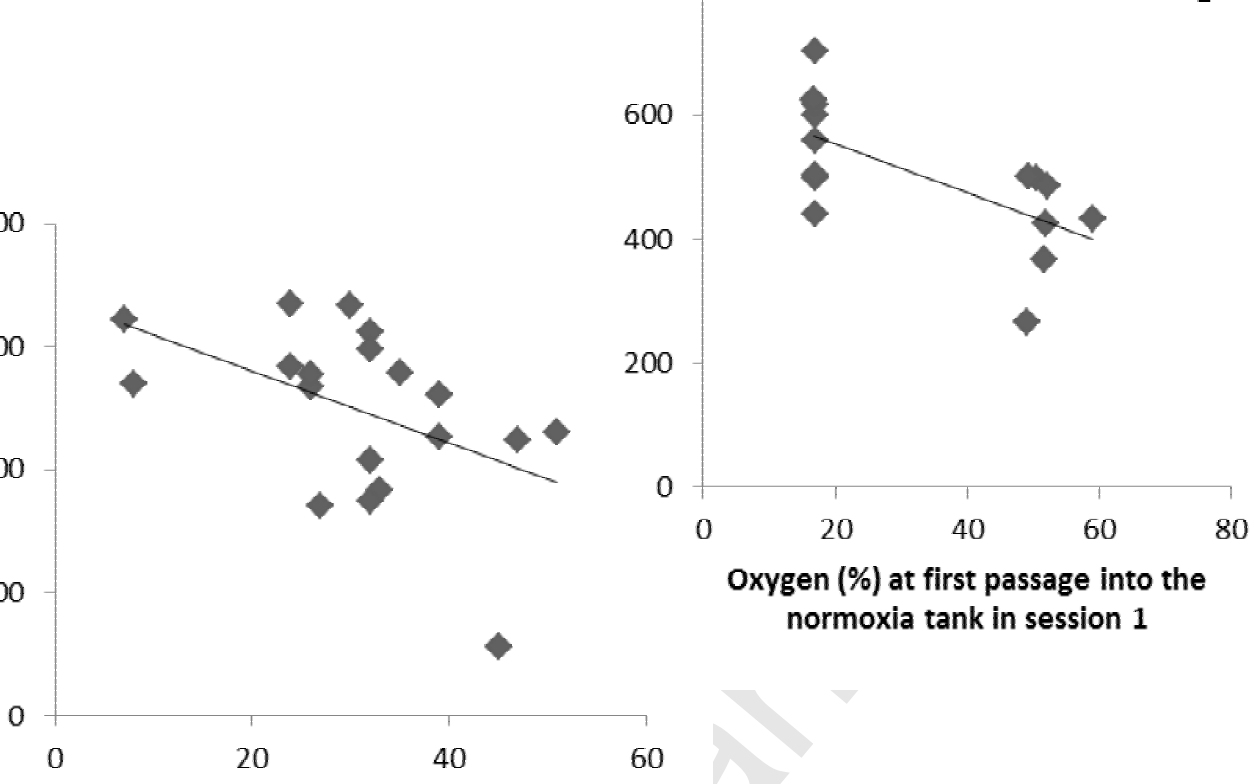

Number of escape attempts in session 1

948

949

950 